(C) 2020, American Psychological Association. This paper is not the copy of record and may not exactly replicate the final, authoritative version of the article. Please do not copy or cite without authors' permission. The final article will be available, upon publication, via its DOI: https://doi.org/10.1037/law0000301

Allegations of Family Violence in Court:

How Parental Alienation Affects Judicial Outcomes

Jennifer J. Harman, PhD

Colorado State University

Demosthenes Lorandos, PhD, JD

PsychLaw.net

Acknowledgements

The authors would like to thank Amanda Sharples, PhD for aiding with the statistical interpretation of the analyses and feedback. We would also like to thank the many undergraduate research assistant coders who were involved with the project: Davien Torres, Alondra Faudoa, Savannah Abbott, Akshira Weiser, Andrew Wilmont, Kylie Morse, Lauren Quintana, Maddie Foster, Alexander Van Sertima, Megan Keller, Emily Story, Jedediah Knode, Simone Yin, Tayla Wilson, Katie Regan, Ellie Stavropoulos, Lindsay Walker, Jordyn Alturafi, Amelia Hadad, and Breanna King. Finally, we would like to thank the law office and PsychLaw team coders: Bruce Bielawa, Shamara Boines, Raphael Dominguez, Gabriel Hinman, LeAnn Scott, and Sarah Vasquez as well as PsychLaw research attorney Melissa Blevins and paralegal Elle Murphree. No external funding was received for this project. Results from this project have not yet been disseminated or made publicly available at the time of this writing. All project materials for this study are available on Open Science Framework:

https://osf.io/j9bh5/?view only=fc6a8223317745e59fc7058543185058 


\begin{abstract}
We tested a set of findings reported by Meier (2019) related to the use of parental alienation (PA) as a legal defense in cases in which there are allegations of domestic violence and child abuse. A total of 967 appellate reports in which PA was found or alleged were sequentially selected from a legal database search. Nineteen research assistants blind to the study's hypotheses coded the reports for the variables used to test six pre-registered hypotheses using a series of logistic and linear regression models. We failed to find any support for the conclusions made by Meier (2019). Parents found (versus alleged) to alienate their children, regardless of their gender, had greater odds of losing parenting time, losing custody of their children, and losing their case. These findings held even when the accusing parent had been found to have been abusive. Losses or decreases in custody were not found when the (alleged) alienated parent was found to have been abusive. Results indicate that the majority of courts carefully weigh allegations of all forms of family violence in their determinations about the best interests of children. These findings, along with several others, raise concerns that the methodological, analytical, and statistical problems we detail about Meier's report (2019) make her conclusions untrustworthy. Discussion focuses on the importance of using open science practices for transparent and rigorous empirical testing of hypotheses and the dangers of misusing scientific findings to mislead influential professionals who affect the well-being of millions of families.
\end{abstract}

Key words: Parental alienation; child abuse; domestic violence; child custody; judicial decision-making 


\section{Allegations of Family Violence in Court: How Parental Alienation Affects Judicial Outcomes}

Parental alienation (PA) refers to a mental condition in which a child allies strongly with one parent and rejects a relationship with the other parent without legitimate justification (Bernet \& Lorandos, 2020). Parental alienation is an outcome of what some scholars have considered a form of family violence (Harman, Kruk, \& Hines, 2018) that is characterized by the perpetration of parental alienating behaviors by an alienating parent (e.g., derogating the alienated parent, Baker \& Darnall, 2006; Harman \& Matthewson, 2020). While parental alienating behaviors are a primary cause of the child's alienation, they are not always the only source. For example, children may adopt and then share the alienating parent's negative attitudes, making them active participants in the rejection of the alienated parent (e.g., Warshak, 2003), and institutions and social systems may contribute to the problem with prolonged response times to violations of court orders or a failure to recognize and intervene when the problem is present (Harman et al., 2018). Parental alienating behaviors are very harmful to children and their extended family members (Harman et al., 2018; Djikstra, 2019; BochGallhau, 2018), which has led to a call for action for more research and interventions that employ a child protection response to the problem (Harman et al., 2018; Kruk, 2018).

Despite over three decades of research that have led to what is considered a scientific maturing, or "greening" of the field and understanding of PA (Harman, Bernet, \& Harman, 2019a), there remain some vocal opponents to recognizing PA as a form of family violence. These opponents have referred to PA as being based on "junk science" (Faller, 1998; Silberg, 2013; Silberg and Dallam 2019), a "pseudoscientific" theory (Meier, 2019), as being a justified dislike for a parent and no different than estrangement (Hoult, 2018), and as being ambiguous and not diagnosable (Scott \& Emery, 1987). PA theory has also been described as a legal strategy used by abusive parents (typically fathers) to obtain custody of their children (Meier, 2019; Silberg, 2013). Other scholars have argued that these claims made by opponents have been largely unsubstantiated, presented as strawman arguments, are 
supported by methodologically flawed research (see as examples Baker, 2020; Haines, Matthewson, \& Turnbull, 2020; Harman et al., 2019a), and have hindered progress to address a serious public health problem (Vezzetti, 2016; Boch-Galhau, 2020).

Joan Meier and colleagues have claimed that PA legal defenses serve to nullify the abuse concerns of mothers, even in the face of expert child abuse evaluations (Meier, Dickson, O'Sullivan, Rosen, \& Hayes, 2019, p. 2). To support their position, the authors presented a review of over 2,000 trial and appellate court rulings published over a 10-year period in a law school research paper series that does not appear to be peer-reviewed. The authors stated that their paper brought "neutral empirical data" to bear on the controversy about "whether and to what extent it is true that courts are disbelieving abuse claims and removing custody from parents claiming abuse, whether and to what extent gender impacts these findings, and how cross-claims of parental alienation affect courts' treatment of mothers' and fathers' abuse claims" (p. 4). Meier et al. (2019) reported that mothers who claimed their children were abused were more likely to lose custody of their children and their legal cases than fathers. They also stated that their hypotheses were supported in their data because fathers who claimed they were alienated were more likely to get custody of their children, even if they were proven to be abusive (p. 15).

After careful inspection of the Meier et al. (2019) research paper, we identified at least 30 conceptual and methodological problems with the design and analyses of the study that make the results and the conclusions drawn dubious at best. The severity of these methodological and analytical problems raises the concern that Meier et al.'s (2019) research paper is being used as a "woozle," which is a belief or claim that has been repeatedly cited and presented in misleading ways (Nielsen, 2014). For this paper, we will first describe the ways that the Meier et al. (2019) paper is being used as a woozle. We will then detail the conceptual, methodological, design, and analytic problems of their study, and 
finally, we will present the results of a pre-registered, transparent, and methodologically rigorous study designed to test some of findings related to PA as reported by Meier et al. (2019).

\section{Woozling}

Woozles are faulty, partial, or misinterpreted research claims that can be used to mislead professionals and others working with families (Nielsen, 2015). These woozles are not supported or are only partially supported by empirical evidence (Gelles, 1980), and they are created by a constellation of factors such as the misrepresentation of other's data and confirmation bias (Nielsen, 2014). We share Nielsen's concern that many woozles are ideologically motivated, magnified, and widely disseminated such that they overshadow studies that challenge them (Nielsen, 2015).

In the research paper, Meier et al. (2019) make many inaccurate and misleading statements that have the potential to woozle scientifically naïve audiences. In media reports, Meier appears to be woozling by minimizing or failing to discuss the limitations of her report (Johnston, 2007; Bonessi, 2019; Schmidt, 2019). An underlying assumption that is repeatedly cited throughout the report is the premise that the concept of parental alienation "was created specifically as a rationale for rejecting child sexual abuse claims" (p. 14). This statement is a misrepresentation of the works of Richard Gardner, who originally coined the term parental alienation syndrome (PAS) (later simplified to PA; Gardner, 1985). Gardner noted that when children are being alienated from a parent, false allegations of abuse are often used to harm their relationship (Gardner, 1987), although in the majority of cases in which he found PAS to be present, a sex-abuse accusation was not alleged (Gardner, 1998). At the time this seminal work was published, the American Academy of Child and Adolescent Psychiatry (1988) also noted stark increases in allegations of child sexual abuse, raising concerns that allegations should not always be accepted as true, particularly during child custody disputes. Gardner never recommended applying the PAS term if there was bona fide child abuse by the rejected parent (Gardner, 1985, 1987), and evidence- 
based assessments continue to require that child abuse be ruled out as a cause for the child's rejection of a parent for PA to be diagnosed (Baker, Bone, \& Ludmer, 2014; Freeman, 2020).

When Gardner's original work was published, it was not received well by child abuse advocates who held the belief that children never lie about abuse (Rand, 2013). Child sexual abuse was portrayed by critics as being an essential feature of PAS (Faller, 1998). Even in the face of decades of research documenting support for his original work (see Rand, 2013), critics have still chosen to misrepresent Gardner's work (e.g., Bruch, 2001). Without citing evidence to support their claim that the concept of parental alienation was created to reject child abuse claims, Meier et al. (2019) imply that Gardner and other scholars who pioneered the concept had malignant motives, which is tantamount to an ad hominem attack. Meier et al. (2019) claim that their research findings provide "evidence" to support this misrepresentation of PA, despite many methodological flaws that make the validity of the work questionable and have prompted us to conduct the current study.

The way Meier and colleagues (2019) discuss the "crediting" of abuse claims throughout the report reflects an alignment with critics that all claims of abuse made by children or "protective parents" should be believed. The authors fail to acknowledge studies that indicate parents, regardless of gender, often make false claims of abuse to gain a custody advantage (Clawar \& Rivlin, 2013; Dunn \& Hendrick, 1994; Harman et al., 2018; Harman \& Matthewson, 2020; Hines \& Douglas, 2016). For example, a thorough analysis of 7,672 child maltreatment investigation cases found that one-third of the investigations were unsubstantiated, and the proportion of allegations shown to be fabricated was $12 \%$ in cases where a contact or residence dispute had occurred (Trocmé, \& Bala, 2005). Ceci and Bruck (1995) also report around half of abuse allegations in divorce are probably false. Despite this research, Meier and colleagues (2019) cite a paper where child sexual abuse claims made in custody litigation are likely valid more than half the time (p. 10, see Faller, 1998, but see Bielaska v Orley, 1996). Nevertheless, this data document that a large proportion of allegations are still false. Meier et al. (2019) never address 
the fact that the parents in her data set may have been lying about abuse, which is a parental alienating behavior (Baker \& Darnall, 2014; Harman \& Matthewson, 2020).

To further matters, Meier et al. (2019) report that guardians ad Litem (GALs) and custody evaluators were not likely to credit mothers abuse claims (pp. 20-21) and need to be educated to "deconstruct misconceptions" about the use of PA claims when child abuse is alleged by mothers (p. 26). This position implies that all claims of abuse made by mothers should be taken at face value and fails to acknowledge that these third parties have had access to considerably more information than what is reported in the judicial reports the research team reviewed. These third parties may have concluded that allegations made by the accusing parent were not substantiated and were, instead, strategies used to obtain a custody advantage. When GALs or custody evaluators reject an abuse claim, this is not necessarily an indication they are untrained or biased. The data presented by Meier et al. (2019) does not support such a conclusion.

Meier et al. (2019) also utilize consensus effects to woozle the reader into placing faith in their findings. For example, the authors state that protective parents and their attorneys have claimed that GALs and custody evaluators fail to recognize abuse, yet no references were cited to support this statement. The portrayal that "consensus" and "many experts" believe something based on anecdotal evidence makes it appear to the reader that there is general agreement on a topic when there is not (Neilson, 2015). In addition, Meier et al. (2019) woozle the reader into believing that some of their findings were statistically significant when they were not, such as highlighting in bold numerous results for which there were no odds ratios presented (and thus not statistically significant, p. 19 footnote).

Finally, Meier et al. (2019) go well beyond their limited data to suggest recommendations that "warrant action" which is a woozling strategy that entails making policy recommendations by relying on one or a few studies and ignoring other relevant research on the topic (Nielsen, 2014; 2015). The 
authors state that courts and affiliated personnel need to be "educated" about their findings that alienation theory plays a "significant role in the denial of child abuse claims" (p. 26); that child protection workers need to stop discrediting claims of abuse made by mothers in child custody disputes (p. 26); and that the U.S. Congress should amend the Child Abuse Protection Act (CAPTA) so that the application of PA theory is prohibited (p. 27).

Given Meier et al.'s (2019) call to action that could affect many influential individuals in institutions that make decisions affecting families (e.g., legislators), it is imperative that a transparent and rigorous test of their hypotheses be conducted to determine whether the findings they reported can be substantiated. To accomplish this task, we first identified thirty conceptual, methodological, and analytic flaws in the research paper and considered how the flaws may have impacted the validity and reliability of the author's findings and conclusions. We then developed a new method and analytic plan that would accurately test the study's hypotheses and overcome the limitations of their study. Below, we briefly describe the flaws we identified and refer the reader to Table 1 for a more thorough description of each and how our study was designed to address them.

\section{Selection of cases}

One of the most striking problems with Meier et al.'s (2019) research paper is how the legal cases for two datasets were selected, leading to what may be a "cherry picked" sample that is stacked in favor of the hypotheses that were described. There was a lack of transparency about the search terms used to select cases and processes by which they were developed in the original paper. The inclusion/exclusion criteria for the cases appeared biased because the Meier team deliberately selected the "cleanest" and most "paradigmatic" cases involving abuse and alienation. The Meier et al. (2019) paper also notes that a large number of cases were excluded that reflect a significant proportion of postdecree appellate cases, such as cases where both parents claim the other is abusive. There were no 
details provided about the coders who selected the cases and how they were trained. In addition, some trial-level cases were included in the database, with no information about whether they were tied to appellate-level judgements made for the same case, which would violate assumptions of independence of the data in the analyses.

For the current study, we provide clear details about the search terms used. The same cases may have appeared in both Meier's (2019) datasets, so our database only contains cases where PA was at issue or raised as a concern because all our hypotheses pertain to this situation. We did not exclude cases regarding custody disputes, relocation issues, joint custody, mutual claims of abuse, third party abuse allegations, non-specific abuse cases, and AKA cases (which Meier (2019) describes as cases where parental alienating behaviors are described), because we felt it important for the database to contain the full spectrum of cases in which PA was alleged or found so that our findings have greater external validity. We also did not include trial-level cases that could be related to the appellate cases to prevent violations of independence of the data.

\section{Coding of the dataset}

No details were provided by Meier et al. (2019) as to who was responsible for coding the two datasets presented in the paper, how discrepancies were resolved, nor their methods used to ensure accuracy. Clear definitions of the codes were also lacking, and it was unclear how some codes were determined. For example, Meier et al. (2019) did not describe in their research paper how they coded multiple allegations of abuse from the same case, as only information about whether there was a claim made or not was reported. For our study, we provide full details about our codebook, who our coders were, and employed quality checks to ensure that they were blind to hypotheses before and after coding the appellate cases. We followed a strict calibration protocol for training on the use of the code book, have all materials publicly accessible on the Open Science Framework (OSF) (e.g., raw coding 
sheets, the codebook) and provide details on how discrepancies were resolved. Meier et al. (2019) also stated that corroborations of abuse in their coding included arrests, protection orders, and prosecutions, without considering the possibility that the parent may later have been found innocent of their allegations. We utilized stringent criteria in our coding manual as to what was determined by the court and other investigating authorities (e.g., police, child protection workers) to be actual abuse. Such a finding would not imply biases by the court as Meier et al. (2019) claim, if the judgements were made based on the preponderance of evidence presented.

\section{Data analysis}

Meier et al. (2019) state that spreadsheets of the coded data were sent to a statistical consultant for analysis, and the analytic plan and statistical codes are available in Appendix $\mathrm{C}$ which was not published with the paper. Specific details on variables and why particular control variables were used were also not provided in the Meier et al. (2019) paper. Without variable details or information about distributions of the data, it is not possible to determine whether the analytic strategy used was appropriate. The lack of transparency calls into question whether the analyses were executed correctly and/or whether the data were "massaged" to support her hypotheses. Another concern was whether Meier et al.'s (2019) hypotheses were created post-hoc to explain statistically significant findings-their hypotheses were not preregistered. We detail thoroughly below the full analytic models and variables that were preregistered on OSF, prior to our data coding and analysis.

\section{Results}

Statistical results were reported largely as percentages of cases in different categories throughout the Meier et al. (2019) report, and odds ratios were reported only for statistically significant analyses. No model fit statistics were provided for any of the logistic regressions that were conducted. Meier et al. (2019) also do not report what $p$-value was used to determine statistical significance for 
most of her statistics (e.g., $p<.05)$. Also, it was not clear whether separate model tests were conducted for group comparisons and how many there were, leading to the potential for type one errors (false positives). Throughout the report, Meier and colleagues often described odds ratios as likelihoods or probabilities. Odds ratios represent how one event is more or less likely than another, while probability represents how likely an event is out of all possible outcomes. When the frequency for the event under investigation is low, odds ratios can make the likelihood of a rare event seem more common than it actually is. This is another form of woozling (Nielsen, 2015) because it is misleading to make the statistical effect appear much larger than it is. We provide all model fit statistics for our analyses and use the correct terminology to explain our results to not woozle readers into misunderstanding the meaning of the statistical findings. All data and syntax used to conduct the analyses are available on OSF.

Given the sampling, coding, and analytical problems described above, it is highly likely that Meier et al.'s (2019) interpretation of their findings is plagued by confirmation bias, which is another way that woozling occurs (Nielsen, 2015). If generalizations and recommendations for administrative (e.g., CPS) and legal institutions are based on biased research, considerable damage may be caused for families. To prevent the woozling of personnel who make so many important decisions regarding the welfare of children and families, this OSF pre-registered study provides an objective, transparent and methodologically rigorous test of the hypotheses related to parental alienation described by Meier et al. (2019).

\section{The current study}

The timeline within which we completed this project is important to detail. The Meier et al.'s (2019) research paper was published on the SSRN website (https://ssrn.com/abstracte=3448062) on September 5, 2019. Due to concerns with the methods and statistics reported in the paper, a member of our research team contacted Meier between September 24 and $30^{\text {th }}$ of 2019 and asked for the 10-line 
LEXIS search string, the coding manual, the full list of the 4,338 cases coded, Appendix B, and Appendix C that were referred to in the paper. Meier questioned the inquirer's affiliation, asked what the proportion of men and women were in her professional practice, and then directed her to archives of the National Institute of Justice for the requested information, which is the institution that funded her project. ${ }^{1}$ We were notified by the funder that data was to be submitted by grantees at least 90 days before the end of their grant periods, which for the Meier et al. grant was June 30, 2019. In other words, although the data and materials were supposed to be available on the archive by April $30^{\text {th }}$ of 2019 , the materials were not yet accessible at the time of our inquiry in September of 2019, and Meier informed us she had "no idea" when they would be available. ${ }^{1}$ After being denied our request for this information directly from her, we registered our emails with the archive's website to be notified when the requested materials would become available. We were left to our own devices to determine Meier et al.'s (2019) hypotheses, research methods, and statistical models, using only what was reported in their paper.

On January $19^{\text {th }}, 2020$, we pre-registered our hypotheses, methods, and analytic plan on OSF. This pre-registration was created to minimize the potential for ideological biases which may influence methodological choices and research conclusions. From the end of January through early July 2020, our research team coded, checked, and entered all the data for this study. Analyses for the study were completed and the results and discussion sections of the paper were completed by the end of the summer of 2020. It was not until October 19, 2020 that we became aware that Meier and colleagues posted some of the materials we had requested (a year previously) onto the archive website. However, not all the information we had requested was available on the website. The notification system had failed to inform us when these materials were made available on August 27, 2020, and at that point our entire project had been completed.

The only Meier et. al. (2019) materials that were available for download from the archive at the time of this writing were the "user manual" that provides details on code definitions, the search terms, 
inclusion/exclusion criteria, and frequencies for the variables. The list of cases, statistical models, and output still did not appear to be available. Although the source of the data is publicly accessible (published court reports), and the project has been funded by public tax dollars, the database access is severely restricted. The requestor must meet many qualifications (e.g., have an appointment at a research institution, have an academic degree and institutional review board approval) and fulfill numerous activities (e.g., provide a reason for the request, sign confidentiality pledges) to gain access to the data (see https://www.icpsr.umich.edu/web/NACJD/studies/37331).

Therefore, a true replication of Meier et al.'s (2019) study has not been possible over the last year given the paucity of information available about the authors' methods and statistics. Our review of the limited information uploaded to the archival website at the end of August 2020 raised more, rather than allayed our concerns about the study's design and findings than we initially detailed prior to the pre-registration of our study. For example, the search term provided was extremely long and specific, yet yielded over 10,000 cases when we attempted to replicate the search using the same database the authors' stated was used for their initial search. There were also not specific details about how many cases were excluded from this initial search using the long list of exclusion criteria listed. The list of exclusion criteria for cases and reasons for discounting claims of abuse in the user manual contained many details that had not been described in the paper, and only served to heighten our concerns about the cherry-picking of data and biased definitions of codes. Although syntax was provided to show how particular variables were scored, it is unclear what the values of the final variables are, whether they are dichotomous or continuous, etc.

Our study design, which provides a direct and thorough test of Meier et al.'s (2019) hypotheses related to parental alienation, is detailed below. The study was designed to address the methodological limitations of Meier et al.'s (2019) study that were described in the research paper. After our review of the partial material that is now publicly accessible, we determined that the methodological flaws 
identified in Table 1 remain unchanged (in fact we found more), and that our study, as designed, provides a stronger and more transparent test of the hypotheses. The execution of the method (procedures, analyses) was followed exactly as specified, and updates, coding sheets, data files, SPSS syntax and output (including model fit statistics), and other related materials are all publicly available on OSF (https://osf.io/i9bh5/?view only=fc6a8223317745e59fc7058543185058).

Hypotheses. We tested a more formally specified and expanded set of hypotheses related to PA cases than Meier et al. (2019), who only outlined a series of research questions that they later said were "tested." Without providing justification for the testing of some very specific relationships, the authors appear to also have developed hypotheses post-hoc to explain statistically significant findings. For example, Meier and colleagues reported testing a hypothesis that when a mother makes a claim of sexual abuse and child abuse, and at least one of them was founded, she was more likely to lose parenting time than a father. HARKing (hypothesizing after results are known) is a seriously questionable research practice that threatens the credibility of research results (Murphy \& Aguinis, 2019), and so we pre-registered our hypotheses prior to data collection to ensure that we could conduct confirmatory, rather than exploratory tests of our hypotheses. Six main hypotheses (and one corollary hypothesis) were tested that specifically examined whether there are gender differences in judicial outcomes for appellate cases in which parental alienation was either alleged or found to be an issue. ${ }^{2}$

Hypothesis six was the only hypothesis that was unique to this study, as we wanted to test whether unfounded allegations of abuse toward a targeted/alienated parent would result in decreases in or loss of parenting time for the targeted/alienated. Meier et al.'s (2019) five other hypotheses were written to test whether these negative consequences affected the parent accused of alienating their children. False or unfounded allegations of abuse against the targeted/alienated parent are often a strategy used by alienating parents to gain or obtain custody of their children (Harman \& Matthewson, 
2020), so we added the sixth hypothesis to test for this effect. For sake of brevity, each hypothesis is detailed fully in Table 2, along with the variables and model tests that were used to test them.

\section{Method}

Selection of cases. Two samples of appellate cases in which PA was "found" or "alleged" to have occurred were drawn from a full set of appellate cases created for a separate project unrelated to the current investigation (Lorandos, 2020). “Alleged" cases were those where PA was alleged by someone but was not found by an expert or the court to have happened, such as a parent claiming they were being alienated from their child. "Found" cases were cases in which an independent evaluating expert (e.g., a psychologist) is noted as having found PA to be an issue in the case, or the court came to this determination after reviewing the evidence presented in the case. The cases were selected from a database inquiry using the ALLSTATES WestLaw database. The search query was: ((alienat! /s (mother father son daughter parent!))) \& DA(aft 12-31-1984 \& bef 01-01-2019). In plain English, the query searched for:

1) any word fragment that contained 'alienat' (which could include alienate, alienated, alienating, or alienation);

2) the 'alienat' word fragment appeared within the same sentence as with one of these words: 'mother,' 'father,' 'son,' 'daughter' or the root word fragment 'parent;' and

3) the case was released and available between January 1, 1984 and December 31, 2018.

This initial search strategy resulted in 3,555 cases. There was considerable variability in the judgments about whether a case involved PA because some cases involved only allegations of PA, while others were corroborated by an expert or evidence presented in court. Six legal assistants (three men, three women) evaluated each case as to whether it involved an independent evaluating expert (e.g., a psychologist) who testified about PA, whether PA was found by the expert, or if the court itself found that there was PA based on the evidence presented (with or without expert testimony). Four of the 
assistants were law school graduates, one was a forensic psychology doctoral candidate, and the other was a paralegal with a bachelor's degree and over ten years of legal research experience. The second author, a legal expert on PA, had monthly research meetings with the team to review the cases to determine whether they would be classified as what was eventually labeled the "FOUND PA" dataset. This classification process resulted in 1,181 cases where an expert or the court determined parental alienation had been found to have occurred in the case.

The remaining 2,374 cases contained those where PA was alleged (but not found by an expert or the court), cases where PA was referenced in relation to other cases rather than the appellate case itself, and cases in which the root word "alienat" was not referencing PA (e.g., alienation of property, alienation of partner affections). A Microsoft Word search using "alienat" as the root word was applied to the judgment entries to determine whether the root word(s) in each were related to PA. This sorting process eliminated cases that do not involve PA or where it was not raised as an issue by someone for the appeal case itself. After eliminating these cases, the final "ALLEGED PA" database contained only cases in which PA was mentioned or alleged by any party involved with the case (e.g., parent) but was not supported or found to be at issue in the case (aka 'not credited').

One paid female legal research assistant who had been trained by the second author and was blind to the study's hypotheses sorted the legal cases for both datasets by date and year of entry. Although fathers were overrepresented as alienated parents in the full dataset ( $75 \%$ of cases, Lorandos, 2020) we aimed to select equal numbers of cases for male and female (alleged) targets of PA because all our hypotheses involved testing for gender differences in outcomes. Working chronologically from December 31, 2018 backwards, 250 cases each from the FOUND PA and ALLEGED PA datasets in which the mother was the alienating parent, and 250 cases from each dataset in which the father was the alienating parent were planned for selection $(N=1,000)$. This prioritization for more recent versus older cases was because recent judgments have considerably more detail provided and have greater 
potential to incorporate scientific advances in the field of PA in the testimony and conclusions made by the experts and court officials. After these cases were sequentially selected, the appellate report for each case was shared with the first author and her research team for coding and analysis.

The datafile. Next, an Excel datafile was created where details for each case were entered: 1) the sequential number assigned to the case; 2) known or alleged database subset; 3 ) the name of the case; 4) the state where the appellate case was heard; 5) year; 6) gender of the alienating parent (alleged or found); and 7) number of minor children directly involved in the appellate case decision (not other children indirectly affected, such as step-siblings).

The codebook. A codebook was created that captures the variables tested in our statistical models. This codebook is presented in Appendix A. Adobe fillable pdf coding sheets were created with fields for each variable where research assistants entered data derived from their close examination of the appellate case reports (see the data mining task described below). For the sake of brevity, only those variables used to test the study's hypotheses are described here.

Party/Parties who alleged parental alienation was coded as any individual who was specifically mentioned as raising the issue of parental alienation in the case but was not an expert or court appointed custody evaluator (e.g., a parent, extended family member). Party/Parties who found parental alienation was coded as any individual who was an expert appointed by the court to evaluate the family (e.g., custody evaluator). If the court determined parental alienation was an issue and no other individual (parent or otherwise) was mentioned, then "court" was entered as the party who found PA after evaluation of the evidence presented in the case. Otherwise, court was not listed in the field. Basis for parental alienation opinion or rejection were fields where the opinion of the court was entered as to whether they determined parental alienation was found or not. This opinion was not always in agreement with the individuals who alleged or found parental alienation. In other words, if a custody 
evaluator found parental alienation, the court may not have come to this conclusion, but the case was still classified having been "found" by an expert or court appointed professional as being an issue. When no explicit opinion was provided, "not addressed" was entered in the field. Custody change at trial level and/or appellate level was a description of the change in residential/physical custody of the children at both levels. If no change was made, then "n/a" was entered in the field.

Did a parent lose all custody of the child(ren) was entered using a dropdown menu with "Yes" or "No/Don't know" options. "Yes" was selected if the parent lost all parental rights, or their parenting time was so severely restricted it was only a few hours a month or less as supervised or therapeutic visitation. This loss had to occur or be affirmed at the end of the appellate decision; in other words, if their loss of custody occurred prior to the trial level motions being heard, then "no" was entered. If a parent did lose custody, then the parent(s) who lost custody were entered into another field (some cases involved both parents losing custody). Winner was a Meier et al. (2019) code for who won the appeal. There was a dropdown menu where coders could select whether the mother or father won the case, the mother or father lost the case, both won or lost the case, or another outcome could be entered (e.g., foster mother won the case).

Allegations of abuse were coded in detail, with one pdf form completed for every single allegation described in the report. While many fields were coded for each allegation (see Appendix A), the fields used for this current study were the type of abuse alleged (domestic violence, child physical abuse, child sexual abuse, neglect, or other), who the party was that was making the allegation, who the allegation was made about, and the outcome of the investigation(s). The exact wording used to describe the outcomes (e.g., false allegation, substantiated or unsubstantiated) were entered, or else "unknown" was entered in the field. Pre-registered hypotheses involving the other variables that were coded on this form are being tested in a forthcoming paper. 
Coding of appellate case reports. A team of 19 research assistants (RAs) comprised of advanced undergraduate psychology students ( 14 female, 5 male) was trained by the first author for the "data mining task". These unpaid RAs earned university credit for completion of the work. To ensure that the RAs were blind to the study's hypotheses, they were asked to write in detail what they believed the hypotheses were after being trained to use the codebook, and again after they completed all coding. Their guesses about the hypotheses for each coder are available on OSF. ${ }^{3}$ While there were not any RAs who correctly guessed the hypotheses, two coders were assigned to each case so that any potential biases that would interfere with their data mining task were minimized.

The RAs practiced coding a sample of five cases from the original search that were not included in the study's sample. Once coded, the team met to review their codes, explain and discuss discrepancies, and the codebook was then clarified. Then, another five cases (not from study dataset) was coded to compare and identify misapplication of the coding scheme, or specific elements of the case that were overlooked (e.g., footnotes that contained relevant information). Feedback was given to coders individually if fields were regularly misapplied until such mistakes no longer occurred.

The data mining task was not a subjective categorization or evaluation of the material, so thoroughness and accuracy were the goals rather than interrater reliability. ${ }^{4}$ After two randomly assigned coders completed the coding forms for each case, another RA identified those fields that were discrepant between the coders, and then the first author reviewed these fields to determine from the original appellate report which information that had been entered into the field was correct. The final coded forms were then saved and entered onto an Excel spreadsheet. All coded and final pdf forms are available on OSF.

Calculation of variables for analyses. We present all the variables for the analyses in Table 3, along with how specifically each were scored and/or calculated. Research process notes were also kept 
to document coding decisions (also available on OSF). It is important to note that the "abusive parent" variable was coded with a dummy code of 1 if there were any findings of abuse by any party toward the parent who was accusing the other parent of alienating them from their child. The burden of proof for making a finding of abuse can be based on something as little as an "inarticulable hunch" of a CPS caseworker (Redleaf, 2019), and so our coding of this variable as a "founded" allegation was quite liberal. There may have been unreported details in the case to indicate that the finding was later deemed unfounded or false and the "abusive" parent may not actually have been abusive.

\section{Results}

Although the initial sample size planned for the study was 1,000 cases, there were 14 cases where the alienating parental figure was not a biological or adoptive parent (e.g., a foster parent, aunt, grandparent). These 14 cases were not included in the hypothesis testing but are included in the sample description because they provide rich details about the types of cases seen at the appellate level that involve allegations or findings of parental alienation. In addition, there were fewer appellate level cases (33 cases) in the original search where the father was found or alleged to be the alienating parent than mothers. Therefore, our final contained 967 cases, of which 953 were with a mother or father as one of the found or alleged alienating parents. Of the 953 cases where a mother or father was the alienating parent, 245 were cases where the father was found to have alienated the children, and 213 were where PA was alleged and not found. After the nonbiological parental figure cases were excluded from the analyses, there were 247 cases where the mother was found to have alienated the children, and 248 where it was alleged and not found. ${ }^{5}$

In the full dataset, there were appellate cases from every state of the U.S., as well as the District of Columbia and the U.S. Territory of Guam. The largest percentage of cases were from more densely populated states, such as New York (11.9\%), California (8.3\%) and Pennsylvania (7.1\%). The remaining 
states represented $\sim 6 \%$ or fewer cases of the sample. There were approximately 1,711 children in the families that were in the appellate cases, of which 898 were from cases where PA was determined to have been found. There was great variability in the types of cases that were heard at the trial level, ranging from divorce and modification of custody and support orders, to requests for termination of parental rights, contempt, and jurisdictional issues. Many appellate cases were appeals of two or more trial level motions: 206 had two motions that were appealed, 29 had three, and four cases had four motions. The trial level motions reflect the diversity of cases in which parental alienation concerns are raised in U.S. family courts. We present numbers for each type of case in Table 4.

There was also great diversity in the number and role of the individual(s) who alleged or found parental alienation across the cases, which are presented in Table 5. Thirty-one cases had no information about who raised parental alienation as an issue. Of the remaining 936 cases, 830 had only one party raise it as a concern, 82 cases had two individuals, 10 had three, and one case had four individuals indicate they believed or found it to be an issue for the family. Interestingly, 263 cases (28.1\%) involved the court determining parental alienation was an issue, which was a code that was only applied when there were no others who were described as raising it as a concern. This finding indicates that nearly one-third of the cases in the sample had a court come to the determination that parental alienation was an issue for a family, independent of any other party (the parent or a court-appointed evaluator). Interestingly, of the cases where a court appointed custody evaluator or GAL determined that parental alienation was occurring $(n=151)$, the court disagreed with their assessment $16.6 \%$ of the time. ${ }^{6}$ Again, these cases were still classified as PA having been "found" because an court appointed professional/expert determined it to be an issue; there did not need to be agreement with the court and these experts about this determination.

Of the cases where the court concluded independently or explicitly agreed with the expert/custody evaluators that parental alienation had occurred $(n=225), 21.3 \%$ involved a situation 
where the alienated parent had at least one allegation of abuse (e.g., domestic violence, child abuse, neglect) that was founded. These types of cases have been labeled "hybrid" cases by professionals, where a child may have a legitimate reason for resisting contact with a parent because they were found to have been abusive in some form, and the other parent engages in alienating behaviors (e.g. Greenberg, Schnider, \& Jackson, 2019). Our data indicates that such "hybrids" represent only about $1 / 5$ of parental alienation cases seen at the appellate level, assuming all the findings of abuse were true.

The mean number of abuse allegations (whether substantiated or not) made about the mothers across the sample was $0.66(S D=1.62$, range $=19)$. Nearly $70 \%$ of the cases $(69.3 \%)$ did not involve any allegations of abuse for mothers, while $17.8 \%$ had one allegation and $6.2 \%$ had two. In contrast, the mean number of allegations made about the fathers across the sample was $1.46(S D=7.95$, range $=$ 233). A little over $50 \%$ of the cases involved no allegations of abuse toward the fathers $(57.5 \%)$, and $20.8 \%$ involved two allegations (the remaining number of allegations represented $9 \%$ or fewer cases). The difference in the number of allegations of abuse alleged toward mothers and fathers was statistically significant, with fathers being alleged abusers more than mothers, $t(966)=-3.14, p=.002$. Those allegations that were substantiated or explicitly found by investigators or the court to be unsubstantiated/false/not credible were examined separately in the testing of our hypotheses. Importantly, 188 cases (19.4\%) involved allegations of abuse being made about both mothers and fathers. These types of cases were deliberately eliminated from Meier et al. (2019) dataset, making nearly $20 \%$ of cases heard at the appellate level unrepresented in her sample.

Changes in physical custody were common across the cases, regardless of the reason for the trial level motion. At the trial level, $69 \%$ of the 967 cases had some form of physical custody alteration (e.g., shared parenting to alternating weekends), and $12.9 \%$ of these cases had an alteration at the appeal level, either reversing the trial level order, or ordering the initial request of the petitioning parent that had been denied at the trial level. Across the cases, $20.3 \%$ involved one parent losing all custody of 
their children, either through termination of their parental rights, or having limited supervised visitation to a few hours a week or less. Approximately $40 \%$ of the cases (390/963) involved an alienating parent (alleged or found) losing $20 \%$ or more of their parenting time after the trial level and appeals process, and $41.2 \%$ of 962 had no change in their amount of physical custody of the children. One hundred and seventy-six (of $963,18.3 \%$ ) parents who alleged or were found to have been alienated from their child(ren) lost $20 \%$ or more of their parenting time.

Around one quarter of cases involved both parents winning or losing their appeal (236 of 966) because the case involved divorce or multiple motions/points of appeal that were considered by the court. One third of the appeals were lost by both mothers (294/966) and fathers (298/966), and between six and seven percent of cases were won by each (67/966 mothers; 57/966 fathers). Fourteen appellate cases were won by another party (e.g., foster parent, a GAL).

\section{Pre-registered hypothesis testing}

All pre-registered hypotheses and the statistical models used to test them are presented in Table 2. The full Excel database, SPSS file, and SPSS syntax and output are available on OSF. A set of three-predictor logistic models were fitted to the data to test all the study's research hypotheses except hypothesis two, which was analyzed with a linear regression because the number of unfounded allegations of abuse was a continuous outcome. "Known" or "alleged" alienating parent cases and gender of the alienating parent were entered as independent variables into all the models, as well as interaction terms for the two variables. The regression analyses were carried out using IBM SPSS statistics package version 26 (IBM Corp, 2019). Decrease in parenting time was an ordinal variable with three levels (increase of $20 \%$ or more parenting time, decrease of $20 \%$ or more parenting time, or no change) and so multinomial logistic regression models were used for that dependent variable. Loss of 
custody and whether a parent lost their case were dichotomous dependent variables and so binary logistic regression analyses were used to test those dependent variables.

Unless specified below, all model fit statistics were good, indicating that the models were more effective than the null model. Tables 6-13 provide specific model fit statistics and outcomes for the models with statistically significant findings (other specific model outcomes, observed and predicted case percentages, etc., were excluded here for the sake of brevity but are available on OSF).

Hypothesis 1. The first pre-registered hypothesis we tested was whether mothers who are perceived to be undermining the father's paternal rights and alienating their child(ren) are more likely to get a decrease in parenting time, lose custody of her children, and lose her case than a father. We did not find support for this hypothesis. According to Table 6, the only significant predictor in the multinomial logistic regression model testing decrease in parenting time was whether the case had been identified as having a known or alleged alienating parent. Regardless of the gender of the parent, a known rather than alleged alienating parent had an $88 \%$ greater probability $(O R=0.128)$ of losing than gaining parenting time $(p<.001)$. This finding implies that parents known to have alienated their child(ren) had more than a 10-fold increase in the likelihood they would lose rather than gain parenting time. A known alienating parent rather than an alleged alienating parent also had $50.4 \%$ lower odds $(p=$ .001 ), or a $66.8 \%$ lower likelihood of having their custody remain the same than lose parenting time.

Similarly, the results of the binomial logistic regression indicate that if there was a known alienating parent, this parent had 2.41:1 greater odds (70.64\% greater likelihood) of losing custody of their children than an alleged alienating parent $(p=.002$; see Table 7$)$. This finding means that when a parent was a known alienating parent, their odds of losing custody increased 2.5 times. We also found a statistically significant gender main effect, such that fathers had 1.73 greater odds $(63.30 \%$ greater likelihood) of losing custody of their child(ren) than mothers $(p=.002)$. The interaction effect 
was not statistically significant. Therefore, mothers who were alleged or found to be an alienating parent were less likely to lose custody of their child than a father, and parents who were found to have alienated their children, no matter the gender, were more likely to lose custody.

Both main effects were statistically significant in the model examining who lost the appellate court case. Fathers had $26 \%$ lower odds of losing their case than mothers $(57.41 \%$ lower probability, $p<$ $.001)$, and parents found to have alienated their child(ren) had twice the odds of losing their case than those who were alleged $(p<.001$, see Table 8$)$. The interaction effect was also statistically significant, in that fathers who were known alienating parents had $21 \%$ lower odds (55.89\% lower likelihood) of losing their case than mothers who were known alienating parents ( $p=.002$; see Table 8$)$.

\section{Hypothesis 1a}

Hypothesis one's corollary hypothesis was that the results would remain statistically significant even if the accusing/alienated parent was found to have been abusive. We narrowed the sample so that any case where the known or alleged alienated parent had a finding of abuse against them was used in the analyses. This restriction brought the sample size to 122 cases. We again did not find support for this hypothesis. Due to this substantial decrease in sample size, the model fit for the multinomial regression was not as good as the test of the first hypothesis (e.g., $\chi^{2}(6)=10.76, p=.096$; See Table 9). The only statistically significant effect in this model was that when a parent was accused rather than found to have alienated the child(ren) and the other parent had at least one finding of abuse toward them, their odds of losing custody rather than gaining custody were $69.4 \%$ lower. In other words, parents who were found rather than accused to be an alienating parent had a $76.56 \%$ lower likelihood of gaining rather 
than losing parenting time when the other parent had a finding of abuse. There were not statistically significant gender differences or interaction effects in the model.

In the model testing loss of custody, there was a statistically significant main effect for gender of the alleged or known alienating parent. Fathers had 2.33 higher odds $(p=.037)$ of losing custody of their children than mothers, even when the mother had a finding of abuse against her. This finding means that the probability of a father losing custody of his child(ren) when the mother had a finding of abuse against her was $69.97 \%$ higher than for mothers in a family where the father had a finding of abuse. Parents found to have alienated their child(ren) had 2.45 greater odds of losing custody of their children than parents who had been alleged to be alienators $(p=.028)$ if there had been a finding of abuse made about the other parent (see Table 10). In other words, when a parent was found to be alienating their child(ren) from the other parent and the other parent had some finding of abuse at some point, they were $70.97 \%$ times more likely to lose custody than parents who were only alleged to be alienating parents. We did not find a statistically significant interaction effect in this analysis.

When an (alleged) alienated parent had a finding of abuse, the only predictor in the model as to whether the known or alleged alienating parent lost their case was their known or alleged status. This finding means that parents known to have alienated their child(ren) had over twice the odds of losing their case than those who were only alleged, if there was a finding of abuse against the other parent $(p=$ .002). Therefore, parents who were known to be alienating their child(ren) had a $67.91 \%$ greater probability of losing their case than an alleged alienating parent if the other parent had a finding of abuse against them. There were no other statistically significant effects in the model.

\section{Hypothesis 2}

The second hypothesis was that when mothers claim intrafamilial abuse and the father claims parental alienation, her reports of abuse will be deemed unfounded more often than if the father 
claimed abuse and the mother claimed PA. To test this hypothesis, a linear regression was calculated to predict the number of unfounded allegations of abuse based on the gender of the parent and whether the case was known or alleged. A statistically significant interaction effect between known and alleged cases of parental alienation and gender would lend support to the hypothesis. We restricted our analysis to include only cases in which a parent made a claim of abuse toward the other parent $(n=336)$ and a significant regression equation was found $(F(3,333)=5.630, p=.001)$, with an $R^{2}$ of 0.220 . The only significant predictor of an unfounded allegation of abuse was gender $(\beta=-0.199, \mathrm{Cl}-1.063$ to -0.341$)$, such that the number of unfounded allegations of abuse was higher for fathers than mothers $(p<.001)$, regardless of whether they were a known or alleged alienating parent ( $p s>.05) .{ }^{7}$ In other words, fathers were more likely than mothers to have unfounded allegations of abuse made about them. Due to a failure to find a statistically significant interaction effect, we did not find support for hypothesis 2 .

\section{Hypothesis 3}

The third hypothesis was that when mothers claim intrafamilial abuse and the father claims parental alienation, she will be more likely to have a decrease in parenting time or lose all custody than if the father claimed abuse and the mother claimed she was being alienated from her children. We again restricted the sample to only those cases where an allegation of abuse toward a parent was made by the other. We failed to find support for this hypothesis. As shown on Table 11, there was only one main effect in the model testing decreases in parenting time; the interaction effect was not statistically significant. Parents known to be an alienating parent and who made an allegation of abuse against the other parent had $86.1 \%$ greater odds ( $87.79 \%$ greater likelihood) of losing parenting time than gaining it compared those who were accused of being an alienating parent $(p<.001)$. There was not a statistically significant interaction effect. Likewise, known alienating parents who made an allegation of abuse against the other parent had $47.4 \%$ greater odds ( $65.53 \%$ greater likelihood) of losing parenting time 
than maintaining the status quo compared than those who were accused of being an alienating parent $(p=.039)$.

A binary logistic regression analysis was conducted to test the hypothesis for loss of custody using only cases where an allegation of abuse was made. Both main effects were statistically significant but the interaction effect was not. Fathers, compared to mothers, had 1.60 greater odds $(61.54 \%$ greater probability) of losing custody if they made an allegation of abuse against the mother ( $p=.048)$. Parents found versus accused of having alienated their child(ren) and who made an allegation of abuse against the other parent had almost three times the odds of losing custody of their child(ren) $(\mathrm{OR}=2.82$, 73.84\% greater probability; $p<.001$, see Table 10$)$.

\section{Hypothesis 4}

The fourth hypothesis was that if a guardian ad litem (GAL), a court appointed psychologist, or custody evaluator were to identify/find parental alienation in a case, mothers will lose more parenting time or custody than fathers. The sample of cases was restricted to those where a custody evaluator or GAL made a finding of parental alienation $(n=176)$ and the same models used to test the third hypothesis were calculated. We failed to find support for this hypothesis (all $p s>.05$ ). There were no statistically significant predictors in the models for decreases in parenting time or loss of custody. Mothers did not get decreases in parenting time or lose custody more often than fathers when a GAL or custody evaluator was involved with the case, whether they were found to be alienating parents or not. The output for these analyses is available on OSF.

\section{Hypothesis 5}

The fifth hypothesis was when a mother claims that both child abuse and sexual abuse occurred and one or both were corroborated, she is more likely to be penalized than fathers by getting a decrease in parenting time or lose all custody. Our careful coding of all allegations of abuse reported in each case 
$(2,080$ allegations total) included a close examination of factors such as who investigated each type of claim, findings of the investigations across multiple parties or institutions (e.g., police, CPS, therapists), and court determinations about the abuse (criminal and family court). Across all the cases in our database, we only identified three cases (one for a mother and two for a father) in which an allegation of sexual abuse and child abuse was made and one or both was found to be substantiated. The abusive parents were not given even partial custody of the children in any of those cases. Due to the small number of cases that were identified, we could not test the hypothesis as specified. Therefore, we created a variable of any substantiated allegation of child abuse, whether it was neglect, sexual, physical, or emotional abuse. We felt this was a better test of the hypothesis because children should be protected from an abusive parent, regardless of the type of abuse.

There were only 77 cases in which a substantiated claim of abuse was found toward a parent that was alleged or found to have been alienated from their child by the other parent, so the model fit for both regression analyses was not ideal. None of the predictors in the models was statistically significant, so gender and known/alleged alienating parent were not related to a decrease in custody if there was a finding of child abuse against the other parent $(p s>.05)$. Therefore, we did not find support for this hypothesis. The output for these statistical analyses is available on OSF.

\section{Hypothesis 6}

Our last hypothesis was that the greater number of false allegations of abuse a mother makes, the more likely it is for the father to have a decrease in parenting time or lose all custody. To examine whether the number of unfounded allegations affected the outcomes, we added this continuous variable and an interaction effect of unfounded allegations and gender of parent alleged or found to be alienating the child(ren) as independent predictor in the models. ${ }^{8}$ If we were to find a statistically significant interaction effect, then there would be support for this hypothesis. 
We found that the more unfounded allegations made about a parent by a known or alleged alienating parent, the more likely the known or alleged alienating parent was to get an increase rather than a decrease in custody (43.6\% lower odds of getting a decrease compared to an increase, or a 63.93\% lower likelihood of receiving decreased parenting time compared to gaining parenting time, $p=$ .022). In other words, the more unfounded claims of abuse that were made against a parent, the accused parent was more likely to get a decrease than increase in parenting time-increased parenting time favored the accuser. We also found that known alienating parents had 10 times greater odds $(p<$ $.001 ; 90.97 \%$ greater likelihood) of receiving a decrease in parenting time than an increase, and 4.29 greater odds of getting an increase in parenting time than no change at all. We also found a main effect for gender in that alienated fathers had almost 6 times the odds ( $85.67 \%$ greater likelihood) than mothers of getting a decrease in custody than alienated mothers $(p=.031)$. The interaction term was not statistically significant (see Table 14).

Finally, we calculated a binomial logistic regression model using the same predictors and we only found a main effect for gender: fathers were more likely to lose custody of their children than mothers $(p=.036)$. We failed to find a statistically significant interaction effect for loss of custody (table not presented here but statistical output is available on OSF). Therefore, we did not find support for our last hypothesis because both interaction effects were not statistically significant: fathers were more likely than mothers to receive decreases in parenting time and loss of custody than mothers, regardless of whether or not an unfounded allegation was made against them. However, the more unfounded allegations made against a parent, regardless of gender, the more likely they were to get decreases in their parenting time. 


\section{Discussion}

This pre-registered study tested the research findings reported by Meier et al. (2019) related to the use of parental alienation (PA) as a legal defense in family court cases, many of which included allegations of abuse (e.g., domestic violence, child physical and sexual abuse). We identified thirty serious concerns about the conceptual, methodological and analytic strategy used by Meier et al. (2019) to potentially mislead and "woozle" readers using her findings, and these concerns were not alleviated when more details were finally available about the study, a year after it was published and the current study was completed. The purpose of our study was to provide a more robust, transparent, and empirically rigorous test of the hypotheses derived from the Meier et al. (2019) research paper, as well as to test an additional independently proposed hypothesis. Not only did we fail to find support for Meier et al.'s conclusions, we found some effects to be the opposite of what the authors reported.

The first hypothesis tested was whether mothers, more than fathers, would be more likely to lose or have decreases in custody and lose their legal case if the other parent claimed they were being alienated from their children. Our results did not support two of the three outcomes. Parents who were found to be alienating their children were more likely to suffer these negative consequences compared to parents who were only alleged to be doing so. In other words, claiming one is being alienated from a child did not always work as a legal strategy to gain custody of children for either mothers or fathers. Such a claim had to be "founded," and when it was, family courts across the country appear to have taken steps to protect children from this form of abuse. This conclusion indicates that courts recognize the damage that parental alienating behaviors do to children, and that it is not in the children's best interests to have their relationship with the alienated parent undermined or destroyed by the alienating parent. Fathers were also more likely than mothers to lose custody of their child(ren), regardless of whether the mother had been found or alleged to alienate the child(ren) from him. 
We did find gender differences in which parent lost their appellate case, with mothers being more likely than fathers to lose their appeal, and if the mother was found to have been alienating their child(ren), she was more likely to lose her appeal than a father who was found to be alienating the child(ren). This was the only hypothesis of Meier et al. (2019) that was supported in our study, however the meaning of this finding is difficult to interpret. Unlike Meier et al. (2019), we did not exclude appellate cases where there were multiple reasons for the appeal, so our analysis only included cases where one parent lost or won all their reasons for their appeal. The "winning" or "losing" of the appeal also did not necessarily mean it was a bad outcome for the parent in regard to their custody of their child. The trial level motions that were appealed varied considerably, such as pertaining to financial issues (e.g., child support or alimony adjustments, distribution of property) and jurisdictional challenges. Future research should investigate whether the type of appeal and loss of the case had a negative impact on the "loser" by gender and if they were a known or alleged alienating parent.

As a corollary hypothesis, we tested Meier et al.'s (2019) claim that the first hypothesis would remain statistically significant if the accusing parent had been found to be abusive in any way. Utilizing a stringent coding of all allegations of abuse in every case, our results did not support Meier et al.'s (2019) finding. Parents who were found to have alienated their children versus those who were merely accused, were the only ones more likely to have a decrease in parenting time if the other parent had any finding of abuse toward them. Likewise, parents found to have alienated their children were more likely to lose custody of their children than those who were alleged, even when the other parent had a finding of abuse. There were statistically significant gender differences in this effect, but in the opposite direction that Meier et al. (2019) reported. Fathers had a higher likelihood of losing custody of the children than mothers, even if the mother had been found to be abusive. Therefore, if a parent claimed they were alienated and had been found to be abusive, they were not more likely to get more or all custody than the other parent, unless the other parent was found to be alienating their child(ren). A 
possible reason for this result is that some courts may have determined parental alienation of the children was abusive and therefore required an intervention to protect them. Future research could examine whether such statements or findings are made with cases where more details are provided (e.g., trial level cases).

Our second hypothesis examined Meier et al.'s (2019) finding that when mothers claim intrafamilial abuse and fathers claim parental alienation, her reports of abuse will be determined to be unfounded more often than if the father claimed abuse and the mother claimed PA. Our data did not provide empirical support for this hypothesis. Overall, mothers made more unfounded claims of abuse than fathers, which is not surprising given that false allegations of abuse are a form of indirect aggression and women tend to use more indirect forms of aggression than men (e.g., Harman, Lorandos, Biringen, \& Grubb, 2019; Murray-Close, Ostrov, Nelson, Crick, \& Coccaro, 2010). However, our results do not indicate that the allegations were more likely to be unfounded when mothers or fathers alleged PA. In our test of the sixth hypothesis, we also did not find that mothers were penalized as much as fathers for making false allegations of abuse toward the other parent. In fact, our results pointed to an opposite effect: fathers had greater odds of losing parenting time if they made an unfounded claim of abuse compared to mothers.

Similarly, in our test of the third hypothesis, our results did not support the claim that when mothers made an allegation of abuse and the father made an allegation of PA, she would be penalized by a loss of parenting time or custody. Our data supported the opposite result: fathers, regardless of whether they were a known or alleged alienating parent, were more likely to lose custody of their children than mothers if they made an allegation of abuse about the mother. This result may reflect a "backlash" effect (Rudman \& Phelan, 2008), such that fathers face social reprisals for behaving counter stereotypically by accusing mothers of being abusive because there are stereotypes that women are not abusive and that men cannot be abused (see Seelau \& Seelau, 2005). As with the model tests for the 
first hypothesis, parents who were found to be alienating their child(ren) from the other parent and who made an allegation of abuse toward them, regardless of their gender, were more likely to have a decrease in their parenting time or lose custody than parents who were just accused of alienating their children.

Interestingly, almost $1 / 3$ of cases involved the court determining parental alienation was an issue for a family, independent of whether another third party identified it as an issue. When a GAL or custody evaluator identified parental alienation as an issue, mothers were not more likely to lose or receive a decrease in custody of their children. Therefore, the fourth hypothesis was not supported.

The fifth hypothesis regarded when an allegation of sexual abuse plus another form of child abuse was made, and one or both were founded. Meier et al. (2019) stated in their research paper that mothers were more likely to lose parenting time or custody if such a situation occurred. We only identified three cases out of the entire dataset where both types of abuse claims were made about the (alleged) targeted parent and one or both of them was founded. The abusive parent was not given even partial custody in these three cases. Out of the 3.5 million reports of child maltreatment recorded in the U.S. each year, approximately 686,000 children were found to be victims of maltreatment, $78 \%$ of whom were neglected and $11 \%$ were victims of some other form of maltreatment (e.g., emotional abuse; U.S. Department of Health and Human Services, 2012). Meier et al. (2019) excluded neglect and emotional abuse of children cases from their database so as to only include child physical and sexual abuse cases. These cases only represent $18 \%$ and $9 \%$ of all child maltreatment cases respectively in the U.S. (U.S. Department of Health and Human Services, 2012), so it is not surprising that we only identified three cases in our dataset that indicated the parent had a finding of child abuse and/or sexual abuse. The prevalence of child and sexual abuse cases in the general population calls to question the sample size tested in Meier et al.'s (2019) model for this hypothesis. 
We are concerned about how allegations of abuse were "credited" by Meier et al. (2019) due to how unclear the coding descriptions were in the research paper. According to our review of the user manual that was made publicly available at the end of August 2020, her team coded protection orders and arrests as "proof" of guilt, despite the fact that such allegations could later be proven false or unsubstantiated. We ultimately tested hypothesis five using any founded child abuse claim (including neglect and child emotional abuse) as our selection criteria for cases because it would not be good for any child to be placed in the custody of a parent who is abusing them in any way. There were only 77 cases where such a finding was definitively made and referenced in the report, and most cases where allegations of abuse were made were not founded. Due to the small sample size of cases that met this model test criteria, the fit for the models was not good and so we could not ultimately test the hypothesis.

Due to a shared concern about protecting children from abuse, all cases in which a child was placed with a parent found to have been abusive in any way when the other parent had been found to be alienating the child were investigated more closely (16 total cases, 11 with "abusive" fathers, 3 with "abusive" mothers, and 2 where both had findings of abuse). The second author and his legal research assistant investigated each of the cases by contacting the attorneys for the person said to be abusive in each case. The results of this investigation indicate that courts were not placing children in the custody of parents who were actively abusive toward the other parent or child. The claims of abuse were not ignored-they were deliberated with great scrutiny by multiple parties and institutions. When the children were placed with the parent who had a past finding of abuse, it was determined the alleged abuse occurred so far in the past that the children were not at risk, the parent had taken the required steps to remediate the problem, the alienating parent's behaviors were so egregious that the placement with the other parent was the safer alternative, or that the allegation was later deemed false. A memo describing the results of our investigation of these cases is available on OSF. After attempting to test this 
hypothesis, we question the sample size and statistical model tests conducted by Meier et al. (2019), as

well as their argument, based on their findings, that judges are taking children away from protective mothers and placing their children in the custody of abusive fathers. Our empirical evidence did not support this conjecture.

The last hypothesis tested was that the more unfounded allegations made about a father by a mother, the more likely he was to lose parenting time or all custody than when a father made unfounded allegations about the mother. We did not find support for this hypothesis. Our results indicate, however, that fathers were more likely than mothers to have a decrease than increase in their custodial time with their child(ren), and the more unfounded claims of abuse that were made against a parent, the more likely they were to get a decrease than increase in their parenting time. This result provides support to what some professionals have called a weapon, or "silver bullet" in child custody disputes: making an unfounded or false allegation of abuse can be an effective tool for parents (of any gender) to obtain more custody of their children (e.g., Lowenstein, 2012). Interestingly, when a parent who was known to be alienating their child(ren) made unfounded claims of abuse, they were more likely to lose parenting time than those who were accused. This result indicates that courts were able to discern when unfounded allegations were being used by parents to alienate children from the other parent. If the parent was found rather than merely accused to have alienated their children, their use of unfounded allegations of abuse was not effective in gaining more custody; rather, they were more likely to lose parenting time.

\section{Limitations}

Our sample was representative of a wide variety of cases where parental alienation was alleged at the appellate level, not just "paradigm" cases that Meier et al. (2019) selected, making our study high in external validity and generalizability. That said, most trial level cases are not appealed, so a limitation 
of the current study is that it is difficult to determine whether the findings are generalizable to what occurs at the trial level. The purpose of our study was to test Meier et al.'s (2019) research paper findings which were based largely on appellate cases, so we restricted our sample to such cases. In the U.S., trial level courts are not required to publish their rulings, so it was not possible to obtain a representative sample of trial level cases to test our hypotheses. We are currently collecting data from trial level cases in Canada where such detailed reports are publicly available to determine whether our findings replicate at that level.

While about $75 \%$ of the appellate cases where parental alienation was found to have occurred involved mothers as the alienating parent (Lorandos, 2020), it is not clear what the source of this gender disparity is, and whether it also exists at the trial level. The financial and emotional costs associated with judicial appeals are a great deterrent for many parents, and there may also be gender biases in assessment and identification. Research examining trial level cases would be helpful in examining whether such gender disparities exist there. We only identified one case in our database where both parents of the child(ren) were the same gender. As more cases involving same-gender parents are heard in the appellate and trial level courts, it will be important to examine how judicial decisions regarding child custody are made when there have been allegations of PA.

There was also considerable variability in the level of detail provided in the appellate reports, particularly related to allegations of abuse. We were conservative in coding whether an allegation was deemed unfounded, in that an allegation was only entered as unfounded, unsubstantiated, or false if the report explicitly stated this to be the case. At the same time, we were liberal in coding whether a parent was "found" to be abusive in that they were coded as such if they had even one founded allegation, which is a highly discretionary and unconstrained conclusion drawn by investigators (e.g., CPS, Coleman, Dodge, \& Campbell, 2010), and can be influenced by their personal orientations (Ashton, 2004). Had more detail been available in the appellate reports, it is possible that the codes for the 
allegations may have been different, so it will be important to replicate our findings with cases in which more details are provided, such as in trial level reports.

In conclusion, after transparently and rigorously testing six pre-registered hypotheses, our results soundly disconfirmed nearly all the findings we tested from Meier et al.'s (2019) report or discovered the findings to be in the opposite direction claimed by the authors. We identified 30 very concerning conceptual, methodological, and statistical issues with Meier et al.'s (2019) study, and when asked to provide us with appendices and statistical output to evaluate her conclusions, she refused to provide them, questioned the inquirer about who they worked for and what types of clients they represented (mothers or fathers), and referred them to a national archive for the material, where much of the material was still not available at the time of this writing. This response raises concerns about the validity of Meier et al.'s (2019) data and the conclusions that can be drawn from it. Our review of the partial materials now accessible on the archive website for the study also raised more, rather than allayed our concerns.

Unfortunately, Meier et al. (2019) have been extensively disseminating their findings to media and policy makers, have failed to discuss the limitations of their report, have been presenting their findings as definitive proof (e.g., Johnston, 2007; Bonessi, 2019; Schmidt, 2019), and have been communicating to the public that abused mothers are losing custody of children to abusive fathers. For example, a September $27^{\text {th }}, 2020$ Canadian national news outlet cited Meier et al.'s (2019) paper with the headline "survivors of domestic abuse told to keep quiet about it in court or risk jeopardizing child custody" (Carmen, 2020). Such messaging propagates stereotypes about men being abusive and women being victims, both of which were not supported in our study.

Meier et al.'s (2019) call to action in their paper also appears to be influencing advocacy groups. Recently, advocates have been trying to draft legislation that prohibits evidence related to parental 
alienation being used in court (Warshak, 2019). In the Spring of 2020, the first author learned from an inside source of a domestic violence group ("Mom's Fight Back") about the language of a bill being pushed by advocacy groups around the U.S. This bill was written such that it would create legislation requiring professionals to be taught about how "alienation theory" is improperly used to deny abuse and fuel misconceptions about "protective parent" and victim behavior, and that professionals using the theory should be punished in ways such as losing their immunity, face criminal liability actions, and lose their professional licenses and accreditations (Anonymous, March 2, 2020). Given the concerns we have raised about their study and our inability to find empirical support for any of the hypotheses we tested, we feel that the misuse of Meier et al.'s (2019) research findings is unethical. Further, this misuse has the potential to harm millions of parents and children, regardless of gender, who are being alienated from each other by an alienating parent (Harman, Leder-Elder, \& Biringen, 2019).

Independent replications, the use of open science practices, and strong, rigorous research methods are essential not only for the accumulation of reliable scientific evidence. These practices are essential for the development and modification of evidence-based policies and legislation. It can be very dangerous to develop policies and legislation based on one or a handful of research studies, particularly studies that are flawed and based on weak evidence drawn from the use of questionable research practices. Chris Chambers (2017) has stated that "malpractice in any field wastes precious public funding by pursuing lines of enquiry that may turn out to be misleading or bogus" (p. xiv). In fields of inquiry where there are concerns that ideological motivations drive research practices and create bias, we believe it is imperative that researchers utilize open science research practices in their work in order to be considered reliable. We followed these practices to the best of our abilities in the current study, and all of our research activities are documented and openly available to the public on OSF. Our hope is that other researchers in this area will do or be expected to do the same.

Certainly, there are parents who claim they are being alienated from a child when they are not, 
just as there are parents who claim they are being abused when they are not. Some professionals working with families make false positive findings of parental alienation (Warshak, 2019), and domestic violence or child abuse may be missed or overreported due to a poor understanding of the problems and insufficient efforts to reduce biases. Fortunately, our findings indicate that appellate courts do not take all claims of parental alienation or domestic violence/child abuse at face value. These claims are evaluated based on the evidence presented, and parents who were found to have alienated their children were more likely to get a decrease in or lose custody of their children, regardless of gender. We did not find that abusive parents were likely to gain or obtain custody. No system is perfect. Yet we are optimistic, based on the data reported here, that decision-makers can discern when children are at risk for family violence in the many forms it takes, including parental alienation, and are implementing strategies to protect the best interests of children. 


\section{References}

Ali, S., Ali, A., Khan, S. A., \& Hussain, S. (2016). Sufficient sample size and power in multilevel ordinal logistic regression models. Computational and Mathematical Methods in Medicine, 2016, article ID 7329158. http://dx.doi.org/10.1155/2016/7329158

American Academy of Child and Adolescent Psychiatry (1988). Guidelines for the clinical evaluation of child and adolescent sexual abuse. [Position paper]. Journal of the American Academy of Child \& Adolescent Psychiatry, 27, 655-657.

Ashton, V. (2004). The effect of personal characteristics on reporting child maltreatment. Child Abuse \& Neglect, 28, 985-997. https://doi.org/10.1016/j.chiabu.2004.03.012

Baker, A. J. L. (2020). Parental alienation and empirical research. In D. Lorandos and W. Bernet (Eds.), Parental Alienation-Science and Law (pp. 207-253). Springfield, IL: Charles C Thomas Publisher.

Baker, A. J. L., Bone, J. M., \& Ludmer, B. (2014). The high conflict custody battle: Protect yourself \& your kids from a toxic divorce, false accusations \& parental alienation, 101 (2014).

Baker, A. J. L., \& Darnall, D. (2006). Behaviors and strategies of parental alienation: A survey of parental experiences. Journal of Divorce \& Remarriage, 45, 97-124.

Bernet, W. \& Lorandos, D. (2020). Preface. In D. Lorandos and W. Bernet (Eds.), Parental AlienationScience and Law (pp. xiii- xviii). Springfield, IL: Charles C Thomas Publisher.

Bielaska v Orley, 1996 WL 33324080 (Mich. Ct. App. July 19, 1996) findings of a special panel of the Michigan Court of Appeals into Kathleen Faller and her methodology.

Boch-Galhau, W. (2018). Parental alienation (syndrome)- a serious form of psychological child abuse. Mental Health and Family Medicine, 14, 725-739. Available from http://mhfmjournal.com/pdf/MHFM-117.pdf.

Boch-Galhau, W. (2020). Parental alienation- a worldwide health problem. Journal of Case Report \& Imaging, 4, 1-5. 
Bonessi, D. M. (2019, August 8). Fathers are favored in child custody battles, even when abuse is alleged. WAMU. Available from https://wamu.org/story/19/08/19/fathers-are-favored-in-child-custodybattles-even-when-abuse-is-alleged/

Bruch, C. S. (2001). Parental alienation syndrome and parental alienation: Getting it wrong in child custody cases. Family Law Quarterly, 14, 381-400.

Carmen, T. (2020, September 27). Survivors of domestic abuse told to keep quiet about it in court or risk jeopardizing child custody. CBC News. Retrieved from https://www.cbc.ca/news/canada/survivors-of-domestic-abuse-punished-for-talking-about-itin-child-custody-cases-1.5738149

Ceci, S. J., \& Bruck, M. (1995). Jeopardy in the courtroom: A scientific analysis of children's testimony. Washington, DC: American Psychological Association.

Chambers, C. (2017). The seven deadly sins of psychology: A manifesto for reforming the culture of scientific practice. Princeton, NJ: Priceton University Press.

Clawar, S. S., \& Rivlin, B. V. (2013). Children held hostage: Identifying brainwashed children, presenting a case, and crafting solutions. Chicago, IL: American Bar Association.

Coleman, D. L., Dodge, K. A., \& Campbell, S. K. (2010). Where and how to draw the line between reasonable corporal punishment and abuse. Law \& Contemporary Problems, 73, 107-166. https://www.ncbi.nlm.nih.gov/pmc/articles/PMC3805039/pdf/nihms491470.pdf

Dijkstra, S. (2019). 'I did not see my daughter for years:' The impact of coercive control on post-divorce relationships between mothers and children. In M. J. Magalhães, A. Guerrerio, \& C. Pontedeira (Eds.), II European Conference on Domestic Violence (e-book), pp. 48-56. Porto, Portugal: Faculty of Psychology and Education Sciences of the University of Porto.

Dunne, J., \& Hendrick, M. (1994). The parental alienation syndrome: An analysis of sixteen selected cases. Journal of Divorce and Remarriage, 21, 21-38. 
Faller, K. C. (1998). The parental alienation syndrome: What is it and what data support it? Child Maltreatment, 3, 100-107.

Freeman, B. (2020). The psychological assessment of contact refusal. In D. Lorandos \& W. Bernet (Eds.), Parental Alienation - Science and Law. Springfield, IL: Charles C. Thomas Publishers

Gardner, R. A. (1985). Recent trends in divorce and custody litigation. Academy Forum, 29, 3-7.

Gardner, R. A. (1987). The parental alienation syndrome and the differentiation between fabricated and genuine child sex abuse. Cresskill, NJ: Creative Therapeutics.

Gardner, R. A. (1998). The Parental Alienation Syndrome. Cresskill, NJ: Creative Therapeutics, $2^{\text {nd }}$ edition.

Gelles, R. (1980). Violence in the family: A review of research in the seventies. Journal of Marriage and the Family, 42, 873-885. doi: 10.2307/351830

Greenberg, L. R., Schnider, R., \& Jackson, J. (2019). Early intervention with resistance/refusal dynamics and hybrid cases. In L. R. Greenberg, B. J. Fidler, \& M. Saini (Eds.), Evidence-informed interventions for court involved families: Promoting healthy coping and development (pp. 189226). New York: Oxford University Press.

Haines, J., Matthewson, M., \& Turnbull, M. (2020). Understanding and managing parental alienation: A guide to assessment and intervention. New York: Routledge.

Harman, J. J., Bernet, W., \& Harman, J. (2019a). Parental alienation: The blossoming of a field of study. Current Directions in Psychological Science, 1-6. https://doi.org/10.1177/0963721419827271

Harman, J. J., Kruk, E., \& Hines, D. A. (2018). Parental alienating behaviors: An unacknowledged form of family violence. Psychological Bulletin, 144, 1275-1299. doi: http://dx.doi.org/10.1037/bul0000175

Harman, J. J., Leder-Elder, S., \& Biringen, Z. (2019). Prevalence of adults who are the targets of parental alienating behaviors and their impact: Results from three national polls. Child \& Youth Services Review, 106, 1-13. https://doi.org/10.1016/jy.childyouth.2019.104471 
Harman, J. J., Lorandos, D., Biringen, Z., \& Grubb, C. (2019). Gender differences in the use of parental alienating behaviors. Journal of Family Violence, online first September 6, 2019. https://doi.org/10.1007/s10896-019-00097-5

Harman, J. J., \& Matthewson, M. (2020). Parental alienation: How it is done. In D. Lorandos \& W. Bernet (Eds.), Parental Alienation-Science and Law (pp. 82-141). Springfield, IL: Charles C Thomas Publisher.

Hines, D. A., \& Douglas, E. M. (2016). Relative influence of various forms of partner violence on the health of male victims: Study of a help seeking sample. Psychology of Men \& Masculinity, 17, 316.

Hoult, J. (2018). “Parental Alienation" (PA) \& "Parental Alienation Syndrome” (PAS): Science, evidence, admissibility, policy \& effects on children's constitutional and human rights. Federal Bar Association, available from https://federalbarcle.org/product/parental-alienation-syndromepas-science-evidentiary-admissibility-policy-effects-childrens-constitutional-human-rights/.

IBM Corp. Released 2019. IBM SPSS Statistics for Windows, Version 26.0. Armonk, NY: IBM Corp.

Johnston, J. (2007). Introducing perspectives in family law and social science research. Family Court Review, 45, 15-21. doi:10.1111/fcre.2007.45.issue-1

Kruk, E. (2018). Parental alienation as a form of emotional child abuse: Current state of knowledge and future directions for research. Family Science Review, 22, 141-164.

Lorandos, D. (2020). Parental alienation in U.S. courts, 1985 to 2018. In 20/20 on Parent-Child Contact Problems: Concepts, Controversies \& Conundrums - Family Court Review Special Issue. April 2020.

Lowenstein, L. F. (2012). Child custody disputes between parents and allegations of sex abuse: What does the research say? Journal of Divorce \& Remarriage, 53, 194-203. http://dx.doi.org/10.1080/10502556.2012.663267 
Meier, J. S., Dickson, S., O’Sullivan, C., Rosen, L., \& Hayes, J. (2019). Child custody outcomes in cases involving parental alienation and abuse allegations. GWU Law School Public Law Research Paper No. 2019-56. Available from https://ssrn.com/abstracte=3448062

Murphy, K. R., \& Aguinis, H. (2019). HARKing: How badly can cherry-picking and question trolling produce bias in published research? Journal of Business \& Psychology, 34, 1-17. https://doi.org/10.1007/s10869-017-9524-7

Murray-Close, D., Ostrov, J.M., Nelson, D. A., Crick, N. R., \& Coccaro, E. F. (2010). Proactive, reactive, and romantic relational aggression in adulthood: Measurement, predictive validity, gender differences, and association with intermittent explosive disorder. Journal of Psychiatric Research, 44, 393-404. https://doi.org/10.1016/j.jpsychires.2009.09.005.

Nielsen, L. (2014). Woozles: Their role in custody law reform, parenting plans, and family court. Psychology, Public Policy, \& Law, 20, 164-180. Doi: https://doi.org/10.1037/law0000004

Nielsen, L. (2015). Pop goes the woozle: Being misled by research on child custody and parenting plans. Journal of Divorce \& Remarriage, 56, 595-633. http://dx.doi.org/10.1080/10502556.2015.1092349

Pampel, F. C. (2000). Logistic Regression: A Primer. Quantitative applications in the social sciences (book 132). Thousand Oaks, CA: Sage Publications.

Rand, D. (2013). The history of parental alienation from early days to modern times. In D. Lorandos, W. Bernet, \& S. R. Sauber (Eds), Parental Alienation: The Handbook for Mental and Legal Health Professionals, pp. 291-321. Springfield, IL: Charles C Thomas.

Redleaf, D. (2019, January 27). After the hotline call. The Atlantic. Retrieved from https://www.theatlantic.com/ideas/archive/2019/01/problem-child-protectiveservices/580771/ 
Rudman, L. A. \& Phelan, J. E. (2008). Backlash effects for disconfirming gender stereotypes in organizations. Research in Organizational Behavior, 28, 61-79. https://doi.org/10.1016/j.riob.2008.04.003

Schmidt, S. (2019, July 29). A gendered trap: When mothers allege child abuse by fathers, the mothers often lose custody, study shows. Washington Post Magazine. https://www.washingtonpost.com/local/social-issues/a-gendered-trap-when-mothers-allegechild-abuse-by-fathers-the-mothers-often-lose-custody-study-shows/2019/07/28/8f811220af1d-11e9-bc5c-e73b603e7f38_story.html

Scott, E. \& Emery, R.E. (1987). The adversary process and child custody disputes. In L.A. Weithorn (Ed.), The Psychologist as Consultant to the Court in Child Custody Determinations (pp. 23-56). Lincoln, NE: University of Nebraska Press.

Seelau, S. M. \& Seelau, E. P. (2005). Gender-role stereotypes and perceptions of heterosexual, gay, and lesbian domestic violence. Journal of Family Violence, 20, 363-371. DOI: 10.1007/s10896-0057798-4

Silberg, J. (2013, September 30). Crisis in Family Court: Lessons from Turned-Around Cases, Final report to the Office on Violence against Women, Department of Justice. 37 (Sept. 30, 2013), http://www.protectiveparents.com/crisis-fam-court-lessons-turned-around-cases.pdf

Silberg, J., \& Dallam, S. (2019). Abusers gaining custody in family courts: A case series of over turned decisions. Journal of Child Custody, 16, 140-169.

Trocmé, N. \& Bala, N. (2005). False allegations of abuse and neglect when parents separate. Child Abuse \& Neglect, 29 (11), 1333-1346.

U.S. Department of Health and Human Services, Administration for Children and Families, Administration on Children, Youth and Families, Children's Bureau. Child Maltreatment 2012 
[online]. Washington, DC: Government Printing Office; 2012. Available from http://www.acf.hhs.gov/sites/default/files/cb/cm2012.pdf

VanEenwyk, J. (2012, May). Guidelines for using and developing rates for public health assessment. Washington State Department of Health. Available from https://www.doh.wa.gov/Portals/1/Documents/1500/Rateguide.pdf

Vezzetti, V. C. (2016). New approaches to divorce with children: A problem of public health. Health Psychology Open. Advance online publication. http://dx.doi.org/10.1177/2055102916678105

Warshak, R. A. (2003). Bringing sense to parental alienation: A look at the disputes and the evidence. Family Law Quarterly, 37, 273-292.

Warshak, R. A. (2019). When evaluators get it wrong: False positive IDs and parental alienation. Psychology, Public Policy \& Law, 26, 54-68. https://doi.apa.org/doi/10.1037/law0000216 


\section{Footnotes}

${ }^{1}$ Details of the correspondence regarding our request for this, and other information referenced in the report is documented and will be available on Open Science Framework (OSF).

${ }^{2}$ We initially specified seven hypotheses and one corollary hypothesis, but then later realized that hypothesis \#5 was the corollary hypothesis and was therefore redundant. This hypothesis was therefore eliminated.

${ }^{3}$ Four of the coders have continued working on a related study examining Canadian trial level cases so they have not yet provided their post-study hypothesis guesses but will do so after completion of that study.

${ }^{4}$ Our initial plan was to assess interrater reliability; however, it became apparent that the data mining for the task was not subjective and requiring calibration, but rather was a task requiring triple "checks" to ensure accuracy.

${ }^{5}$ After cases were examined in the data mining task with deep scrutiny, there were numerous cases in which the court determined parental alienation occurred or did not occur that were not originally classified in this way. This discrepancy was likely due to our analysis of all the details of the rulings, which resulted in identifying sections of text that were missed by the assistants in the initial identification of cases that featured the issue more prominently in their search terms and case summaries. In 512 cases, the court determined that parental alienation did occur in the family (of which 250 were alienating mothers and 270 were alienating fathers), and there were 247 cases in which the court specifically stated parental alienation was not an issue in the case (144 where the mother and 103 where the father was alleged but not found; the remaining were cases where the courts did not specify an opinion). We analyzed all our hypotheses using this as a predictor separately and this output is available on OSF. The research results were similar to those presented in this paper, however the effects were often stronger. $^{5}$

${ }^{6}$ Due to the way the data was recorded, it was not possible to determine how often custody evaluators or GALs determined parental alienation did not occur and were overridden by the court.

${ }^{7}$ It is important to note that when the same set of analyses were conducted using as a predictor whether the court agreed with the parental alienation assessment or concluded themselves (rather than rejected it as at issue for the family), the gender difference was not statistically significant (output for these analyses is available on OSF). ${ }^{8}$ The original analytic plan restricted cases to when the parent made an unfounded allegation of abuse, however this would not have allowed us to test the hypothesis as written. Therefore, the variable was entered as an independent predictor in the models. We also only included an interaction effect of the unfounded allegations and gender of the alleged or found alienated parent, as this effect would be the crucial test of the hypothesis. 
Table 1

Methodological Flaws of the Meier et al. (2019) Research Paper and Remedies Implemented in the Current Study

\begin{tabular}{|c|c|c|}
\hline & Identified flaw & Problem with the flaw \\
\hline & $\begin{array}{l}\text { 1. Hypotheses were not explicitly } \\
\text { detailed prior to the presentation } \\
\text { of the results. }\end{array}$ & $\begin{array}{l}\text { Failure to explicitly describe hypotheses a priori casts doubt about } \\
\text { whether the researcher engaged in HARKing behaviors (e.g., see } \\
\text { Murphy \& Aguinis, 2019), making her hypotheses exploratory } \\
\text { rather than confirmatory. Consequently, the researcher may have } \\
\text { created hypotheses after finding statistically significant effects, } \\
\text { which may have been statistical artifacts or false positives. }\end{array}$ \\
\hline 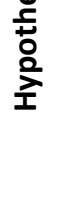 & $\begin{array}{l}\text { 2. Several hypotheses were tested } \\
\text { without any theoretical or } \\
\text { practical rationale detailed in the } \\
\text { introduction. }\end{array}$ & $\begin{array}{l}\text { By not detailing why particular relationships were tested in the } \\
\text { data, there are concerns that the researcher engaged in cherry } \\
\text { picking and "fishing" the data for statistically significant effects that } \\
\text { aligned with the goals of the researcher and create confirmation } \\
\text { biases. }\end{array}$ \\
\hline
\end{tabular}

3. Failure to provide information about the different search engines and databases used to "test" search strings.

4. Failure to provide in the paper the database search string of "over 10 lines of search terms" that were "constructed and applied" (p. 5). ${ }^{1}$

Unclear which search engines were used and what search strings were tested at this stage, and why ultimately LEXIS was selected over the other search engines. Lack of transparency makes replication impossible and may reflect a bias in the selection of the search engine that produced the desired outcomes.

The final search string was not provided. The author did not define what "constructed" and "applied" mean in this context. Lack of transparency makes replication impossible and may reflect a bias in the selection of cases.

5. No information was provided about the coders who "triaged" the initial search cases.

Unclear what training the coders had and whether they were blind to the study's hypotheses. The coders may have been biased in their selection of cases if they knew about the study's hypotheses, and inaccurate in their classification of cases without training and oversight.

Remedy

All hypotheses tested were preregistered on OSF prior to data coding and analysis.

The rationale for this study's hypotheses is to determine whether we could find support for findings reported by Meier (2019). One added hypothesis was included and the justification for testing it was provided.

The cases were selected from the Westlaw (Thomson Reuters) database.

The complete search string used is provided.

Full details about the research assistants' training, oversight, and measures taken to ensure they are blind to the study's hypotheses are provided. 


\section{Identified flaw}

6. Cases in which the parents were of the same sex were excluded from the database

7. Only cases that had three core outcomes were included in the sample: crediting of abuse, custody outcomes, and "wins"

8. Cases were excluded with "third party victims" such as a new or old romantic partner, "mutual abuse" cases, "non-specific" abuse claims, and "AKA" cases, which were cases in which negative parenting behaviors, which are "similar" in analysis to PA cases.

9. No information was provided about the coders who excluded cases at the inclusion/exclusion stage.

10. An expanded dataset of all abuse claims was created, without details of the search terms or search engine used.
Same-sex parents are just as likely to be alienated from their children as those of different sex (Author 1, Leder-Elder, \& Biringen, 2019), and there is no justification for why these cases were excluded. Gender biases toward parents in same-sex couples can occur, so excluding these cases results in a sample that is not representative of all the cases that may be heard at the appellate level. $^{2}$

This sample restriction served to eliminate cases in which courts were addressing visitation (e.g., violations of parenting time), joint custody, and relocation matters, which are often legal interventions for parental alienating behaviors (Author 1 \& Matthewson, 2020). The final sample was not representative of complex cases heard by appellate-level courts, making the generalizability of the findings limited and potentially biased because they were selected to match what Meier (2019) herself considered the "paradigmatic" and "clean" cases involving abuse and parental alienation.

The only rationale for excluding these cases was to have the most "paradigmatic" and "clean" cases involving abuse and parental alienation. Excluding all these cases (1,987 of them) potentially biases the sample and may lead to false conclusions that cannot be generalized beyond the data Meier selected.

Unclear what training the coders had and whether they were blind to the study's hypotheses. The coders may have been biased in their exclusion of cases if they knew the study's hypotheses, and inaccurate in their classification of cases without training and oversight.

Unclear which search engine and search strings were used. Lack of transparency makes replication impossible and may reflect a bias in the selection of cases. ${ }^{3}$

\section{Remedy}

Appellate case reports were not be excluded if the parents in the case are the same sex.

Cases were not eliminated from the sample that pertain to visitation, joint custody, and relocation matters.

Cases were not eliminated from the sample that pertain to third party victims of abuse, mutual abuse cases, non-specific abuse claims, and AKA cases.

Full details about the research assistants' training, oversight, and measures taken to ensure they are blind to the study's hypotheses are provided.

No "pure abuse" dataset will be created for this study because the hypotheses tested are regarding only 
11. Extrafamilial abuse cases were included in the "all abuse" dataset but were excluded in the "analytic dataset."

12. The degree of overlap between the "all abuse" and "analytic database" was not described. ${ }^{11}$

13. Lack of clarity provided about how "non-alienation" and "pure alienation" cases were identified, and how the final numbers for each were determined.

14. Trial-level cases were included in the full dataset.

15. Details about the coders of the datasets are not provided.
By excluding extrafamilial cases in one dataset, but including them in another, the two databases become incomparable.

The two datasets both contained PA cases (p. 19), so it is likely that some of the same cases may have appeared in both sets of analyses. Results presented for the two data sets may have duplicate cases, making the findings redundant to some degree and not independent.

No details were provided about the individuals responsible for classifying cases as "non-alienation" and "pure alienation," so it is unclear what their training was or their understanding of the study's hypotheses. The numbers of cases for each category also do not directly match the number of cases reported as being included in the final samples. Replication of this categorization step is not possible due to the lack of information provided.

No details are provided about the proportion of trial-level cases that were tied to the appellate-level cases in the same dataset. Trial-level cases are not all listed on legal database searches, while all appellate-level cases are. Independence of the data cannot be assumed when some cases are tied, which violates statistical assumptions underlying the use of logistic regression models. The trial-level cases are also not representative of all-trial level cases, making the generalization of findings to that level of cases limited.

Unclear how many coders there were, how they were trained, their level of education, gender, and how much knowledge they had about the study's hypotheses. The coders may have been biased in their coding of the cases.
No extrafamilial abuse cases were excluded from our database.

Only one database was created using cases in which parental alienation was raised as an issue.

Only cases in which parental alienation was raised as an issue were in our dataset.

Only publicly available appellate-level cases were included in the dataset.

Details about coders and their training is provided. 


\section{Identified flaw}

16. Details about how coding discrepancies were resolved are not provided, nor are interrater reliabilities.

17. No details were provided in the paper about the 45 specific codes and options for them that were applied to the cases. ${ }^{4}$

18. Readers are referred to Appendix $B$ to obtain details about the codes used.

19. Lack of clarity was provided in the paper of how codes were defined. ${ }^{12}$

\section{Problem with the flaw}

Unclear how accurate the coders were in the application of the codes, and how discrepancies were resolved. The codes may have been unreliable in their application to the cases, and there may have been biases in how discrepancies were resolved.

Without details about the codes, it was impossible to replicate the coding of the cases for the current study.

Appendix B was not published with the research paper and was not made publicly available until August 27, 2020. The author failed to provide us with the information when requested in the Fall of 2019. This extended delay in provision of the materials required the reader to "trust" the author that the codes are clear and accurately captured the variables under study. ${ }^{12}$ This failure also made replication of the study impossible.

The authors were unclear about how multiple claims of abuse were coded because only "credited" or "not credited" was applied to each case when there was an abuse allegation. "Corroboration of abuse" was described as whether a protection order, arrest, or prosecution of interpersonal violence was made (p. 20). "Proven" cases in the "all abuse" database is also described, but it is unclear who made this determination and how substantiation was determined. Collapsing across multiple claims of abuse into one code of "credited" versus "not credited" for each case fails to document the use of serial abuse allegations in post-decree cases. The way corroboration of abuse is defined assumes that all claims

\section{Remedy}

All coders were blind to the study's hypotheses, and two independent coders completed the data mining task for every case. Their being blind to the study's hypotheses helped to ensure they would not willfully overlook, or input data in a selective way. A third coder identified discrepancies, referred to the original court ruling, and identified the correct response for those fields.

All code definitions are provided for this study.

All codes and definitions are provided for this study and are publicly available on OSF.

All abuse claims were coded for each case and details were recorded as to their substantiation. 
Identified flaw

20. There did not appear to be consistent application of codes across the two datasets.

21. Change in custody is consistently worded throughout the report as whether the mother or father "loses custody" after making an abuse allegation.

22. Readers are referred to Appendix $C$ to obtain details about the analytic plan and statistical codes.

23. Control variables were not clearly described or justified.
Problem with the flaw

Remedy

and formal allegations of abuse are true, even if they later had been

deemed false after investigation or trial.

Corroboration of abuse appears to only have been applied to the "all abuse" dataset, and not the "analytic" dataset. "Credited" abuse and "founded" abuse were described in separate analyses, with "credited" never being defined, and criminal convictions in the "all abuse database" being coded as "credited" for the "all abuse" dataset (p. 20), making it appear that the two codes are conflated for the "analytic" dataset analyses. Lack of clarity of the codes and how they were applied can lead to biases in application, interpretation, and make replicability impossible.

Many judgements involve changing custody from joint to primary custody with one parent or reversing the primary custodial status of the parent. It is not clear whether Meier et al. are considering any negative change as complete loss of custody, which would be an inaccurate depiction of the outcome. ${ }^{5}$ Lack of clarity about how custody loss was defined makes conclusions drawn about this outcome limited.

Appendix $C$ is not publicly available at the time of this writing and was not provided to us when requested of the author. We were informed that the information may not be available on the Department of Justice Archive for up to 9 months after the report was published. Only frequency data for the variables were provided. Failure to provide analysis and statistical information upon request, when Appendix $\mathrm{C}$ will not be available for review for many months after publication of the report, requires the reader to "trust" the author that the analyses were done correctly. This failure also makes replication of the study impossible.

"Control for factors that may affect key outcomes" (p. 7) were mentioned, such as the state in which the case was heard and triallevel versus appellate-level court rulings. No specifics were given about the variables used, and why they were added as control variables. The interpretation of the statistical findings, without
One database was used for this study and the codes were clearly defined and applied consistently across cases.

We coded cases for substantial gain, loss, or status quo regarding custody, as well as identified cases in which all parenting time was lost.

The full analytic plan is provided. All data and syntax have been uploaded onto OSF.

All variables in the calculated models are clearly specified. 
Identified flaw

24. Gender is reported to be included as a control variable (p. 7) in the statistical models.

25. The types of variables used in the model were not described (e.g. continuous, dichotomous, ordinal).

26. The ways variables were dummy coded was not clearly described. ${ }^{13}$

27. No model fit statistics were provided for any of the logistic regressions that were conducted.

28. Adjustments to $p$-values for multiple comparisons (e.g., $p<$ $.01)$ and effect sizes were not provided.
Problem with the flaw

Remedy

possible.

Gender is an independent variable in the models, as all the analyses were testing gender differences. It is unclear why gender would also then be entered as a control variable. The interpretation of the statistical findings, without clarity of the role of gender in the analyses, is not possible.

Without describing what type of variable each factor in the model is, it is not possible to determine whether the analytic strategy used was appropriate.

Without knowing how the variables were dummy coded, it is not possible to evaluate the direction of effects (odds ratios) in the model. Meier (2019) did not provide such statistics, so it is therefore impossible to determine whether her interpretation of the effects was accurate.

Without model fit information, it is not possible to determine whether the models used were appropriate for the data, and what factors in the models were most important.

It was not clear whether multiple comparisons were made, and whether adjustments were made to the $p$-values because the likelihood of false positives (Type I errors) increases with multiple comparisons. The magnitude of the effects is also not possible to determine based on the information provided.
Gender is an independent variable in the analytic models, not a control variable.

All variables are described for our models as to whether they are continuous, dichotomous, or ordinal.

Information on how variables were coded are described in the preregistration materials, and all other decisions are described in an open research process document available on OSF.

All model fit statistics are provided.

A $p$-value of .05 has been used (no multiple comparisons were made). 
Identified flaw

29. Odds ratios are described as likelihoods (e.g., "mothers are 2.48 times as likely to lose custody when an evaluator is present than not," p. 24) when odds and likelihood are not the same concepts.

30. Proportions of cases were continually reported as "rates."

\section{Problem with the flaw}

Odds are ratios of two events, while likelihood refers to number of events divided by the total number of events, which requires a base rate or estimation of the overall occurrence of the phenomenon (ranges from 0 to 1; e.g., Pampel, 2000). Describing odds ratios as probabilities is misleading and makes the statistical effect appear much larger than it is.

Rate refers to the quantity of one dimension (total people affected), divided by another dimension (population at risk) and includes an indication of time (e.g., each year; VanEenwyk, 2012). Proportions are just percentages of cases in the dataset. The terminology used was incorrect and could be potentially misleading to the reader.

\section{Remedy}

Statistical findings were thoroughly described so as to not mislead the reader.

Statistical findings were thoroughly described so as to not mislead the reader. 


\section{Footnotes}

${ }^{1}$ On August 27, 2020, the user manual was finally made available to the public on the archive website. The user manual contained the search term string. We entered this term into the LEXIS/NEXIS database and obtained 10,000+ case results, only 250 of which can be downloaded at a time. Screen shots of this search are available on OSF. The extremely detailed search string did not appear to narrow the search of cases to be included, and it still remains unclear how many cases from this large search were eliminated for the various reasons specified in the paper and user manual.

${ }^{2}$ The user manual referenced in footnote 1 presented many other exclusion criteria for which no explanations or justifications were provided. For example, cases in which custody of children was split between parents, which is an intervention sometimes used by courts to address parental alienation, were excluded in the Meier et al., 2019 database.

${ }^{3}$ The user manual referenced in footnote 1 indicates that the full dataset may have been restricted to only include cases where abuse was credited, but the details about this remain unclear.

${ }^{4}$ The user guide referenced in footnote 1 contained more details about the codes applied, but they were not fully explained, and it was not clear why so many levels were assigned to the values given to each code.

${ }^{5}$ The syntax provided in the user manual described in footnote 1 did not make clear how variable codes were combined to form different types of variables (e.g., continuous, dichotomous). 


\section{Table 2}

\section{Pre-registered Hypotheses and the Analytic Models Tested}

\begin{tabular}{|c|c|c|c|c|}
\hline$\#$ & Hypothesis & Analysis $^{1}$ & Independent Variables ${ }^{2}$ & Dependent Variables \\
\hline $\mathrm{H} 1$ & $\begin{array}{l}\text { When a mother is perceived to be undermining the } \\
\text { father's paternal rights and alienating their } \\
\text { child(ren), she is more likely to get a decrease in } \\
\text { parenting time, lose custody of her children, and } \\
\text { lose her case than a father. }\end{array}$ & $\begin{array}{l}\text { Logistic regression } \\
\text { models }\end{array}$ & $\begin{array}{l}\text { Gender of alienator (M/F) } \\
\text { Founded versus alleged PA case }\end{array}$ & $\begin{array}{l}\text { Decrease in parenting time } \\
\text { Total loss of custody } \\
\text { (Alleged) alienating parent loses } \\
\text { case }\end{array}$ \\
\hline $\mathrm{H} 1 \mathrm{a}$ & $\begin{array}{l}\mathrm{H} 1 \text { results will be statistically significant even when } \\
\text { the alienated parent is proven to be abusive. }\end{array}$ & $\begin{array}{l}\text { Logistic regression } \\
\text { model using only cases } \\
\text { where Abusive Parent } \\
\text { variable }=1\end{array}$ & $\begin{array}{l}\text { Gender of alienator (M/F) } \\
\text { Founded versus alleged PA case }\end{array}$ & $\begin{array}{l}\text { Decrease in parenting time } \\
\text { Total loss of custody } \\
\text { (Alleged) alienating parent loses } \\
\text { case }\end{array}$ \\
\hline $\mathrm{H} 2$ & $\begin{array}{l}\text { When mothers claim intrafamilial abuse in family } \\
\text { court and the father claims PA, her reports of abuse } \\
\text { will be determined by the court to be unfounded } \\
\text { more often than if the father claimed abuse and the } \\
\text { mother claimed PA. }\end{array}$ & $\begin{array}{l}\text { Linear regression using } \\
\text { only cases where Abuse } \\
\text { Allegation variable }=1\end{array}$ & $\begin{array}{l}\text { Gender of alienator (M/F) } \\
\text { Founded versus alleged PA case }\end{array}$ & $\begin{array}{l}\text { Number of unfounded claims of } \\
\text { abuse }\end{array}$ \\
\hline $\mathrm{H} 3$ & $\begin{array}{l}\text { When mothers claim intrafamilial abuse in family } \\
\text { court and the father claims PA, she will be more } \\
\text { likely to have a decrease in parenting time or lose } \\
\text { all custody than if the father claimed abuse and the } \\
\text { mother claimed PA. }\end{array}$ & $\begin{array}{l}\text { Logistic regression } \\
\text { model using only cases } \\
\text { where Abuse Allegation } \\
\text { variable }=1\end{array}$ & $\begin{array}{l}\text { Gender of alienator (M/F) } \\
\text { Founded versus alleged PA case }\end{array}$ & Decrease in parenting time \\
\hline $\mathrm{H} 4$ & $\begin{array}{l}\text { Mothers will have a decrease in parenting time or } \\
\text { lose all custody more often than fathers when a GAL } \\
\text { or custody evaluator is involved in the case. }\end{array}$ & $\begin{array}{l}\text { Logistic regression } \\
\text { model using only cases } \\
\text { where Third Party } \\
\text { variable }=1\end{array}$ & $\begin{array}{l}\text { Gender of alienator (M/F) } \\
\text { Founded versus alleged PA case }\end{array}$ & Decrease in parenting time \\
\hline
\end{tabular}




\begin{tabular}{|c|c|c|c|c|}
\hline$\#$ & Hypothesis & Analysis $^{1}$ & Independent Variables ${ }^{2}$ & Dependent Variables \\
\hline $\mathrm{H}^{3}$ & $\begin{array}{l}\text { When a mother claims that both child abuse and } \\
\text { sexual abuse occurred and one or both were } \\
\text { corroborated, she is more likely to be penalized } \\
\text { than fathers by getting a decrease in parenting time } \\
\text { or lose all custody. }\end{array}$ & $\begin{array}{l}\text { Logistic regression } \\
\text { model using only cases } \\
\text { where Child Abuse } \\
\text { variable }=1^{4}\end{array}$ & $\begin{array}{l}\text { Gender of alienator (M/F) } \\
\text { Founded versus alleged PA case }\end{array}$ & $\begin{array}{l}\text { Decrease in parenting time } \\
\text { Total loss of custody }\end{array}$ \\
\hline $\mathrm{H} 6^{3}$ & $\begin{array}{l}\text { The greater number of false allegations of abuse } \\
\text { that a mother makes, the more likely it is for the } \\
\text { father to have a decrease in parenting time or lose } \\
\text { all custody. }\end{array}$ & $\begin{array}{l}\text { Logistic regression } \\
\text { model }^{5}\end{array}$ & $\begin{array}{l}\text { Gender of alienator (M/F) } \\
\text { Founded versus alleged PA case } \\
\text { Number of Unfounded Claims }{ }^{5}\end{array}$ & $\begin{array}{l}\text { Decrease in parenting time } \\
\text { (alleged) alienated parent } \\
\text { Total loss of custody (alleged) } \\
\text { alienated parent }\end{array}$ \\
\hline
\end{tabular}

\section{Footnotes}

${ }^{1}$ The decrease in parenting time variable has three ordinal levels, so a multinomial logistic regression was used. Total loss of custody and loss of the case were dichotomous, so binary logistic regression models were used.

${ }^{2}$ Interaction terms for the independent variables will also be included in the equation.

${ }^{3}$ Originally, we specified seven hypotheses, but realized after pre-registration of them that our fifth hypothesis was the same model test as hypothesis 1 a.

Therefore, hypothesis five was eliminated, and hypotheses six and seven were renumbered to five and six respectively.

${ }^{4}$ Due to their only being three cases that met the criterion of having at least one of two child abuse or sexual abuse claims substantiated, the models could not be tested as originally planned. We therefore created a variable as the selection criteria of "any founded claim of child abuse" as the predictor, regardless of whether the allegation was neglect, sexual, physical, or emotional abuse.

${ }^{5}$ The original analytic plan had the cases restricted to when the parent made an unfounded allegation of abuse, however this would not have allowed us to test the hypothesis as written. To examine whether the number of unfounded allegations affected the outcomes, we needed to include the continuous variable as an independent predictor in the models, and an interaction term for this variable with gender of the (alleged) alienating parent. 
Table 3

Variable Details for the Analytic Models

\begin{tabular}{|c|c|c|c|}
\hline $\begin{array}{l}\text { Variables used } \\
\text { in analysis }\end{array}$ & Variable Name & $\begin{array}{l}\text { Type of } \\
\text { variable }\end{array}$ & Calculation \\
\hline \multirow{5}{*}{$\begin{array}{l}\text { Restriction of } \\
\text { sample } \\
\text { variables }\end{array}$} & Abuse Allegation & Dichotomous & $\begin{array}{l}\text { If any allegation of abuse was made by the (alleged) alienating parent, the case was assigned a dummy } \\
\text { code of } 1 . \text { If no allegation was made, the case was assigned a dummy code of } 0 .\end{array}$ \\
\hline & Third Party & Dichotomous & $\begin{array}{l}\text { If a GAL or custody evaluator was mentioned as being involved in determining whether parental } \\
\text { alienation occurred in the family, the case was assigned a dummy code of } 1 \text {. If neither is mentioned, the } \\
\text { case was assigned a dummy code of } 0 .\end{array}$ \\
\hline & Abusive Parent & Dichotomous & $\begin{array}{l}\text { If an (alleged) alienated parent had any allegation of abuse (DV, Child Abuse, or Sexual Abuse, neglect, } \\
\text { child maltreatment) toward them that was either substantiated and/or that they were found guilty of by } \\
\text { a court, the case was assigned a dummy code of } 1 \text {. If none are mentioned, the case was assigned a } \\
\text { dummy code of } 0 \text {. }\end{array}$ \\
\hline & Child Abuse Parent & Dichotomous & $\begin{array}{l}\text { If an (alleged) alienated parent had any allegation of child abuse sans DV (Child Physical Abuse, or Sexual } \\
\text { Abuse, Neglect, Child Maltreatment) toward them that was either substantiated and/or that they were } \\
\text { found guilty of by a court, the case was assigned a dummy code of } 1 \text {. If none are mentioned, the case } \\
\text { was assigned a dummy code of } 0 .\end{array}$ \\
\hline & $\begin{array}{l}\text { Unfounded Claims } \\
\text { Only }\end{array}$ & Continuous & $\begin{array}{l}\text { A tally was created of all unfounded/unsubstantiated claims of abuse made by the (alleged) alienating } \\
\text { parent. No tally was created if at least one of the allegations was substantiated or the (alleged) alienated } \\
\text { parent was found guilty (the variable will be missing for these cases). Unknown findings were not } \\
\text { included in this tally, only those allegations that were specifically investigated and reported to have } \\
\text { been false, untrue, or unsubstantiated were coded. }\end{array}$ \\
\hline $\begin{array}{l}\text { Independent } \\
\text { variables }^{1}\end{array}$ & $\begin{array}{l}\text { Gender of (alleged) } \\
\text { alienator } \\
\text { Founded or Alleged } \\
\text { PA }\end{array}$ & $\begin{array}{l}\text { Dichotomous } \\
\text { Dichotomous }\end{array}$ & $\begin{array}{l}\text { If the (alleged) alienator was female, the case was assigned a dummy code of }-1 . \text { If the (alleged) } \\
\text { alienator was male, the case was assigned a dummy code of } 1 . \\
\text { If the case was from the "Founded PA" dataset, it was assigned a dummy code of } 1 . \text { If the case was from } \\
\text { the "Alleged PA" dataset, it was assigned a dummy code of }-1 \text {. }\end{array}$ \\
\hline $\begin{array}{l}\text { Dependent } \\
\text { variables }\end{array}$ & $\begin{array}{l}\text { Decrease in } \\
\text { parenting time }\end{array}$ & Continuous & $\begin{array}{l}\text { A tally was created of all unfounded/unsubstantiated claims of abuse made by the (alleged) alienating } \\
\text { parent. No tally was created if at least one of the allegations was substantiated or the (alleged) alienated } \\
\text { parent was found guilty (the variable will be missing for these cases). Unknown findings were not } \\
\text { included in this tally, only those allegations that were specifically investigated and reported to have } \\
\text { been false, untrue, or unsubstantiated were coded. } \\
\text { If the (alleged) alienating parent was given significantly less parenting time ( }<20 \% \text { change in days) than } \\
\text { they had prior to the trial-level hearing as described in the appellate case, the case was assigned a } \\
\text { dummy code of - } 1 \text {. If the (alleged) alienating parent had the same parenting time as prior to the trial- } \\
\text { level hearing, the case was assigned a dummy code of } 0 \text {. If the (alleged) alienating parent was given }\end{array}$ \\
\hline
\end{tabular}




\begin{tabular}{|c|c|c|c|}
\hline $\begin{array}{l}\text { Variables used } \\
\text { in analysis }\end{array}$ & Variable Name & $\begin{array}{l}\text { Type of } \\
\text { variable }\end{array}$ & Calculation \\
\hline & & & $\begin{array}{l}\text { significantly more parenting time than they had prior to the trial-level hearing (>20\% change in days), } \\
\text { the case was assigned a dummy code of } 1 .\end{array}$ \\
\hline & Total loss of custody & Dichotomous & $\begin{array}{l}\text { If the (alleged) alienating parent lost all parenting time or parental rights, the case was assigned a } \\
\text { dummy code of } 1 \text {. These cases included those where the parenting time was substantially restricted to } \\
\text { supervised visits for only a few hours a month or less. If the (alleged) alienating parent did not lose all } \\
\text { time or rights, the case was assigned a } 0 .\end{array}$ \\
\hline & Lost the case & Dichotomous & $\begin{array}{l}\text { If the (alleged) alienating parent lost their appeal, the case was assigned a dummy code of } 1 \text {. If the } \\
\text { parent won the appeal, the case was assigned a dummy code of } 0 .\end{array}$ \\
\hline & $\begin{array}{l}\text { Decrease in } \\
\text { parenting time } \\
\text { (alleged) alienated } \\
\text { parent }\end{array}$ & Ordinal & $\begin{array}{l}\text { The 'decrease in parenting time' variable was reversed to reflect loss of parenting time for the (alleged) } \\
\text { alienated parent. }\end{array}$ \\
\hline & $\begin{array}{l}\text { Total loss of custody } \\
\text { (alleged) alienated } \\
\text { parent }\end{array}$ & Dichotomous & $\begin{array}{l}\text { The 'total loss of custody' variable was reverse coded to reflect total loss of custody for the (alleged) } \\
\text { alienated parent. }\end{array}$ \\
\hline
\end{tabular}




\section{Footnotes}

${ }^{1}$ Our original planned dummy coding of this variable was 0 and 1 , which would not have allowed us to compare the two groups with the interaction term. Therefore, this dummy code was adjusted to be -1 and 1 . 


\section{Table 4}

Trial Level Motions of the Appellate Cases

Motions

Number of cases

Divorce

160

Modification of custody, decision-making, or parenting time

550

Modification of child support, alimony, or other financial issues

Contempt, enforcement of court orders, show cause, compel

137

Termination of parental rights, name change, emancipation of child, guardianship, adoption

Relocation

Motions to vacate, dismiss, or strike motions or orders

Requests for orders of protection, supervised parenting time and visitation, neglect and

dependency

Other logistical or jurisdictional issues, recusal requests, reconsiderations, requests for evaluations or grandparent visitation

Note. The total number of motions is higher than the number of cases ( $n=967)$ because many of the appeals involved disputes concerning multiple motions that were heard at the trial level. 


\section{Table 5}

Parties who Alleged or Found Parental Alienation

\begin{tabular}{lc}
\hline \multicolumn{1}{c}{ Party } & Number of cases \\
\hline Mother & 204 \\
Father & 304 \\
Court & 263 \\
Guardian ad Litem & 45 \\
Court appointment psychological evaluator & 140 \\
$\begin{array}{l}\text { Mental health, legal professional, or agency representative (e.g., therapist, child } \\
\text { protection worker) }\end{array}$ & 120 \\
Other family member (e.g., step-parent) & 17
\end{tabular}

Note. The total number of third parties represented is higher than the number of cases $(n=967)$ because many of the appeals involved multiple parties alleging or finding parental alienation had occurred. 
Table 6

Multinomial Logistic Regression Analysis: Gender and Known or Alleged Alienating Parent as Predictors of Decreases in Parenting Time

\begin{tabular}{|c|c|c|c|c|c|c|c|c|c|}
\hline \multirow{2}{*}{$\begin{array}{c}\text { Reference category: } \\
\text { Alienating parent } \\
\text { gained parenting } \\
\text { time }\end{array}$} & \multirow[b]{2}{*}{ Predictor } & \multirow[b]{2}{*}{$\boldsymbol{\beta}$} & \multirow[b]{2}{*}{$S E \beta$} & \multirow{2}{*}{\multicolumn{2}{|c|}{$\begin{array}{l}\text { Wald's } \\
v^{2}\end{array}$}} & \multirow[b]{2}{*}{$p$} & \multirow{2}{*}{$\begin{array}{c}e^{\beta} \\
\text { (odds } \\
\text { ratio) }\end{array}$} & \multicolumn{2}{|c|}{$\begin{array}{l}\text { 95\% Confidence } \\
\text { Interval for } \operatorname{Exp(B)}\end{array}$} \\
\hline & & & & & & & & $L L$ & $U L$ \\
\hline & Intercept & 1.841 & 0.224 & 67.299 & 1 & $<.001$ & -- & -- & -- \\
\hline Alienating parent & Gender of known or alleged alienating parent & -0.177 & 0.210 & 0.710 & 1 & .399 & 0.838 & 0.555 & 1.264 \\
\hline \multirow[t]{2}{*}{ lost parenting time } & Known or alleged alienating parent & -2.056 & 0.210 & 96.012 & 1 & $<.001$ & 0.128 & 0.085 & 0.193 \\
\hline & Gender * known or alleged interaction term & 0.233 & 0.210 & 1.230 & 1 & .267 & 1.262 & 0.836 & 1.904 \\
\hline & Intercept & 1.208 & 0.238 & 25.857 & 1 & $<.001$ & -- & -- & -- \\
\hline No change in & Gender of known or alleged alienating parent & 0.091 & 0.203 & 0.198 & 1 & 656 & 1.095 & 0.735 & 1.631 \\
\hline \multirow{2}{*}{ parenting time } & Known or alleged alienating parent & -0.702 & 0.203 & 11.897 & 1 & .001 & 0.496 & 0.333 & 0.739 \\
\hline & Gender * known or alleged interaction term & 0.111 & 0.203 & 0.298 & 1 & .585 & 1.117 & 0.750 & 1.665 \\
\hline Test & & Value & & $x^{2}$ & $d f$ & $p$ & & & \\
\hline \multicolumn{10}{|c|}{ Overall model evaluation } \\
\hline & Likelihood ratio test gender of parent & & & 3014 & 2 & 210 & & & \\
\hline Likelit & & -- & & $3.0+1$ & 2 & .215 & & & \\
\hline & od ratio test known or alleged alienating parent & -- & & 138.216 & 2 & $<.001$ & & & \\
\hline & Likelihood ratio test interaction effect & -- & & 1.369 & 2 & .504 & & & \\
\hline & Akaike information criterion & 59.399 & & & & & & & \\
\hline & Bayesian Information Criterion & 98.276 & & & & & & & \\
\hline & -2 Log likelihood & 43.399 & & & & & & & \\
\hline
\end{tabular}


Table 7

Binary Logistic Regression Analysis: Gender and Known or Alleged Alienating Parent as Predictors of Loss of Custody

\begin{tabular}{|c|c|c|c|c|c|c|c|c|}
\hline \multirow[b]{2}{*}{ Predictor } & \multirow[b]{2}{*}{$\boldsymbol{\beta}$} & \multirow[b]{2}{*}{$S E \beta$} & \multirow[b]{2}{*}{ Wald's $\chi^{2}$} & \multirow[b]{2}{*}{$d f$} & \multirow[b]{2}{*}{$p$} & \multirow{2}{*}{$\begin{array}{c}e^{\beta} \\
\text { (odds } \\
\text { ratio) }\end{array}$} & \multicolumn{2}{|c|}{$\begin{array}{l}95 \% \text { Confidence } \\
\text { Interval for Exp (B) }\end{array}$} \\
\hline & & & & & & & $\boldsymbol{L L}$ & $U L$ \\
\hline Constant & 0.515 & 0.175 & 8.701 & 1 & .003 & 1.673 & -- & -- \\
\hline Gender of known or alleged alienating parent & 0.545 & 0.175 & 9.762 & 1 & .002 & 1.725 & 1.225 & 2.429 \\
\hline Known or alleged alienation case & 0.878 & 0.175 & 25.296 & 1 & $<.001$ & 2.406 & 1.709 & 3.387 \\
\hline Gender * known or alleged interaction term & 0.182 & 0.175 & 1.091 & 1 & .296 & 1.200 & 0.852 & 1.689 \\
\hline Test & Value & & $\chi^{2}$ & $d f$ & $p$ & & & \\
\hline \multicolumn{9}{|l|}{ Overall model evaluation } \\
\hline Likelihood ratio test & -- & & 39.912 & 3 & $<.001$ & & & \\
\hline -2 Log likelihood & 211.279 & & & & & & & \\
\hline \multicolumn{9}{|l|}{ Goodness-of-fit } \\
\hline Hosmer and Lemeshow Test & -- & & 0.000 & 2 & 1.00 & & & \\
\hline
\end{tabular}




\section{Table 8}

Binary Logistic Regression Analysis: Gender and Known or Alleged Alienating Parent as Predictors of Loss of Case

\begin{tabular}{|c|c|c|c|c|c|c|c|c|}
\hline \multirow[b]{2}{*}{ Predictor } & \multirow[b]{2}{*}{$\boldsymbol{\beta}$} & \multirow[b]{2}{*}{$S E \beta$} & \multirow[b]{2}{*}{ Wald's $\chi^{2}$} & \multirow[b]{2}{*}{$d f$} & \multirow[b]{2}{*}{$p$} & \multirow{2}{*}{$\begin{array}{c}e^{\beta} \\
\text { (odds } \\
\text { ratio) }\end{array}$} & \multicolumn{2}{|c|}{$\begin{array}{l}\text { 95\% Confidence } \\
\text { Interval for Exp (B) }\end{array}$} \\
\hline & & & & & & & $L L$ & $U L$ \\
\hline Constant & -0.299 & 0.076 & 15.350 & 1 & $<.001$ & 0.741 & -- & -- \\
\hline Gender of known or alleged alienating parent & -0.298 & 0.076 & 15.227 & 1 & $<.001$ & 0.742 & 0.639 & 0.862 \\
\hline Known or alleged alienation case & 0.745 & 0.076 & 95.096 & 1 & $<.001$ & 2.106 & 1.813 & 2.446 \\
\hline Gender * known or alleged interaction term & -0.237 & 0.076 & 9.647 & 1 & .002 & 0.789 & 0.679 & 0.916 \\
\hline Test & Value & & $\chi^{2}$ & $d f$ & $p$ & & & \\
\hline \multicolumn{9}{|l|}{ Overall model evaluation } \\
\hline Likelihood ratio test & -- & & 124.685 & 3 & $<.001$ & & & \\
\hline-2 Log likelihood & 1033.845 & & & & & & & \\
\hline \multicolumn{9}{|l|}{ Goodness-of-fit } \\
\hline Hosmer and Lemeshow Test & -- & & 0.000 & 2 & 1.00 & & & \\
\hline
\end{tabular}




\section{Table 9}

Multinomial Logistic Regression Analysis: Gender and Known or Alleged Alienating Parent as Predictors of Decreases in Parenting Time in

\section{Cases where the Accusing/Alienated Parents was Found to Have Been Abusive}

\begin{tabular}{|c|c|c|c|c|c|c|c|c|c|}
\hline \multirow{2}{*}{$\begin{array}{c}\text { Reference category: } \\
\text { Alienating parent } \\
\text { gained parenting } \\
\text { time }\end{array}$} & \multirow[b]{2}{*}{ Predictor } & \multirow[b]{2}{*}{$\beta$} & \multirow[b]{2}{*}{$S E \beta$} & \multicolumn{3}{|l|}{ Wald's } & \multirow{2}{*}{$\begin{array}{c}e^{\beta} \\
\text { (odds } \\
\text { ratio) }\end{array}$} & \multicolumn{2}{|c|}{$\begin{array}{l}\text { 95\% Confidence } \\
\text { Interval for } \operatorname{Exp(B)}\end{array}$} \\
\hline & & & & $\chi^{2}$ & $d f$ & $p$ & & $L L$ & $U L$ \\
\hline \multirow{4}{*}{$\begin{array}{l}\text { Alienating parent lost } \\
\text { parenting time }\end{array}$} & Intercept & 0.118 & 0.486 & 0.059 & 1 & .808 & -- & -- & -- \\
\hline & Gender of known or alleged alienating parent & -0.382 & 0.487 & 0.615 & 1 & .433 & 0.683 & 0.263 & 1.773 \\
\hline & Known or alleged alienating parent & -1.183 & 0.487 & 5.905 & 1 & .015 & 0.306 & 0.118 & 0.795 \\
\hline & Gender * known or alleged interaction term & 0.883 & 0.487 & 3.289 & 1 & .070 & 2.418 & 0.931 & 6.278 \\
\hline \multirow{4}{*}{$\begin{array}{l}\text { No change in } \\
\text { parenting time }\end{array}$} & Intercept & 0.000 & 0.500 & 0.000 & 1 & 1.00 & -- & -- & -- \\
\hline & Gender of known or alleged alienating parent & -0.107 & 0.451 & 0.057 & 1 & .812 & 0.898 & 0.371 & 2.174 \\
\hline & Known or alleged alienating parent & -0.161 & 0.451 & 0.127 & 1 & .721 & 0.851 & 0.352 & 2.061 \\
\hline & Gender * known or alleged interaction term & 0.241 & 0.451 & 0.285 & 1 & .593 & 1.272 & 0.526 & 3.080 \\
\hline Test & & Value & & $x^{2}$ & $d f$ & $p$ & & & \\
\hline \multicolumn{10}{|c|}{ Overall model evaluation } \\
\hline & Overall model likelihood ratio test & -- & & 10.762 & 6 & .096 & & & \\
\hline & Likelihood ratio test gender of parent & -- & & 0.644 & 2 & .725 & & & \\
\hline Likeliho & d ratio test known or alleged alienating parent & -- & & 7.055 & 2 & .029 & & & \\
\hline & Likelihood ratio test interaction effect & -- & & 3.556 & 2 & .169 & & & \\
\hline & Akaike information criterion & 44.356 & & & & & & & \\
\hline & Bayesian Information Criterion & 66.789 & & & & & & & \\
\hline & -2 Log likelihood & 28.356 & & & & & & & \\
\hline
\end{tabular}


Table 10

Binary Logistic Regression Analysis: Gender and Known or Alleged Alienating Parent as Predictors of Loss of Custody in Cases where the Accusing/Alienated Parents was Found to Have Been Abusive

\begin{tabular}{|c|c|c|c|c|c|c|c|c|}
\hline \multirow[b]{2}{*}{ Predictor } & \multirow[b]{2}{*}{$\beta$} & \multirow[b]{2}{*}{$S E \beta$} & \multirow[b]{2}{*}{ Wald's $\chi^{2}$} & \multirow[b]{2}{*}{$d f$} & \multirow[b]{2}{*}{$p$} & \multirow{2}{*}{$\begin{array}{c}e^{\beta} \\
\text { (odds } \\
\text { ratio) }\end{array}$} & \multicolumn{2}{|c|}{$\begin{array}{l}\text { 95\% Confidence } \\
\text { Interval for Exp(B) }\end{array}$} \\
\hline & & & & & & & $L L$ & $U L$ \\
\hline Constant & -1.038 & 0.406 & 6.543 & 1 & .011 & 0.354 & -- & -- \\
\hline Gender of known or alleged alienating parent & 0.846 & 0.406 & 4.352 & 1 & .037 & 2.331 & 1.104 & 5.416 \\
\hline Known or alleged alienation case & 0.894 & 0.406 & 4.855 & 1 & .028 & 2.445 & 1.104 & 5.416 \\
\hline Gender * known or alleged interaction term & 0.214 & 0.406 & 0.277 & 1 & .599 & 1.238 & 0.559 & 2.743 \\
\hline Test & Value & & $x^{2}$ & $d f$ & $p$ & & & \\
\hline \multicolumn{9}{|l|}{ Overall model evaluation } \\
\hline Likelihood ratio test & -- & & 9.810 & 3 & .020 & & & \\
\hline-2 Log likelihood & 44.174 & & & & & & & \\
\hline \multicolumn{9}{|l|}{ Goodness-of-fit } \\
\hline Hosmer and Lemeshow Test & -- & & 0.000 & 2 & 1.00 & & & \\
\hline
\end{tabular}




\section{Table 11}

Multinomial Logistic Regression Analysis: Gender and Known or Alleged Alienating Parent as Predictors of Decreases in Parenting Time in

\section{Cases where an Allegation of Abuse was Raised Against the Other Parent}

\begin{tabular}{|c|c|c|c|c|c|c|c|c|c|}
\hline \multirow{2}{*}{$\begin{array}{c}\text { Reference category: } \\
\text { Alienating parent } \\
\text { gained parenting } \\
\text { time }\end{array}$} & \multirow[b]{2}{*}{ Predictor } & \multirow[b]{2}{*}{$\beta$} & \multirow[b]{2}{*}{$S E \beta$} & \multicolumn{2}{|c|}{ Wald's } & \multirow[b]{2}{*}{$p$} & \multirow{2}{*}{$\begin{array}{c}e^{\beta} \\
\text { (odds } \\
\text { ratio) }\end{array}$} & \multicolumn{2}{|c|}{$\begin{array}{l}95 \% \text { Confidence } \\
\text { Interval for } \operatorname{Exp}(B)\end{array}$} \\
\hline & & & & $\chi^{2}$ & $d f$ & & & $L L$ & $U L$ \\
\hline \multirow{4}{*}{$\begin{array}{l}\text { Alienating parent lost } \\
\text { parenting time }\end{array}$} & Intercept & 1.745 & 0.327 & 28.524 & 1 & $<.001$ & -- & -- & -- \\
\hline & Gender of known or alleged alienating parent & -0.403 & 0.310 & 1.685 & 1 & .194 & 0.668 & 0.364 & 1.228 \\
\hline & Known or alleged alienating parent & -1.975 & 0.310 & 40.487 & 1 & $<.001$ & 0.139 & 0.076 & 0.255 \\
\hline & Gender * known or alleged interaction term & 0.475 & 0.310 & 2.340 & 1 & .126 & 1.608 & 0.875 & 2.954 \\
\hline \multirow{4}{*}{$\begin{array}{l}\text { No change in } \\
\text { parenting time }\end{array}$} & Intercept & 0.821 & 0.362 & 5.149 & 1 & .023 & -- & -- & -- \\
\hline & Gender of known or alleged alienating parent & 0.116 & 0.311 & 0.140 & 1 & .708 & 1.123 & 0.611 & 2.066 \\
\hline & Known or alleged alienating parent & -0.642 & 0.311 & 4.263 & 1 & .039 & 0.526 & 0.286 & 0.968 \\
\hline & Gender * known or alleged interaction term & 0.109 & 0.311 & 0.122 & 1 & .727 & 1.115 & 0.606 & 2.050 \\
\hline \multirow{2}{*}{\multicolumn{2}{|c|}{$\begin{array}{l}\text { Test } \\
\text { Overall model evaluation }\end{array}$}} & Value & & $\chi^{2}$ & $d f$ & $p$ & & & \\
\hline & & & & & & & & & \\
\hline & Overall model likelihood ratio test & -- & & 63.512 & 6 & $<.001$ & & & \\
\hline & Likelihood ratio test gender of parent & -- & & 4.420 & 2 & .110 & & & \\
\hline Likelihc & d ratio test known or alleged alienating parent & -- & & 53.658 & 2 & $<.001$ & & & \\
\hline & Likelihood ratio test interaction effect & -- & & 3.128 & 2 & .209 & & & \\
\hline & Akaike information criterion & 52.205 & & & & & & & \\
\hline & Bayesian Information Criterion & 83.852 & & & & & & & \\
\hline & -2 Log likelihood & 36.206 & & & & & & & \\
\hline
\end{tabular}




\section{Table 12}

Binary Logistic Regression Analysis: Gender and Known or Alleged Alienating Parent as Predictors of Loss of Custody in Cases where an

\section{Allegation of Abuse was Raised Against the Other Parent}

\begin{tabular}{|c|c|c|c|c|c|c|c|c|}
\hline \multirow[b]{2}{*}{ Predictor } & \multirow[b]{2}{*}{$\beta$} & \multirow[b]{2}{*}{$S E \beta$} & \multirow[b]{2}{*}{ Wald's $\chi^{2}$} & \multirow[b]{2}{*}{$d f$} & \multirow[b]{2}{*}{$p$} & \multirow{2}{*}{$\begin{array}{c}e^{\beta} \\
\text { (odds } \\
\text { ratio) }\end{array}$} & \multicolumn{2}{|c|}{$\begin{array}{l}\text { 95\% Confidence } \\
\text { Interval for Exp(B) }\end{array}$} \\
\hline & & & & & & & $L L$ & $U L$ \\
\hline Constant & 0.039 & 0.237 & 0.028 & 1 & .868 & 1.040 & -- & -- \\
\hline Gender of known or alleged alienating parent & 0.470 & 0.237 & 3.925 & 1 & .048 & 1.600 & 1.005 & 2.547 \\
\hline Known or alleged alienation case & 1.038 & 0.237 & 19.150 & 1 & $<.001$ & 2.823 & 1.774 & 4.494 \\
\hline Gender * known or alleged interaction term & 0.245 & 0.273 & 1.063 & 1 & .302 & 1.277 & 0.802 & 2.033 \\
\hline Test & Value & & $\chi^{2}$ & $d f$ & $p$ & & & \\
\hline \multicolumn{9}{|l|}{ Overall model evaluation } \\
\hline Likelihood ratio test & -- & & 26.077 & 3 & $<.001$ & & & \\
\hline-2 Log likelihood & 123.050 & & & & & & & \\
\hline \multicolumn{9}{|l|}{ Goodness-of-fit } \\
\hline Hosmer and Lemeshow Test & -- & & 0.000 & 2 & 1.00 & & & \\
\hline
\end{tabular}




\section{Table 13}

Multinomial Logistic Regression Analysis: Unfounded Allegations, Gender, and Known or Alleged Alienating Parent as Predictors of Decreases

\section{in Parenting Time in Cases}

\begin{tabular}{|c|c|c|c|c|c|c|c|c|c|}
\hline \multirow{2}{*}{$\begin{array}{c}\text { Reference category: } \\
\text { Alienating parent } \\
\text { gained parenting } \\
\text { time }\end{array}$} & \multirow[b]{2}{*}{ Predictor } & \multirow[b]{2}{*}{$\beta$} & \multirow[b]{2}{*}{$S E \beta$} & \multirow{2}{*}{$\begin{array}{c}\text { Wald's } \\
\chi^{2}\end{array}$} & \multirow[b]{2}{*}{$d f$} & \multirow[b]{2}{*}{$p$} & \multirow{2}{*}{$\begin{array}{c}e^{\beta} \\
\text { (odds } \\
\text { ratio) }\end{array}$} & \multicolumn{2}{|c|}{$\begin{array}{l}\text { 95\% Confidence } \\
\text { Interval for } \operatorname{Exp(B)}\end{array}$} \\
\hline & & & & & & & & $L L$ & $U L$ \\
\hline & Intercept & -2.682 & 0.470 & 31.520 & 1 & $<.001$ & -- & -- & -- \\
\hline Alienating parent & Unfounded allegations & -0.573 & 0.249 & 5.284 & 1 & .022 & 0.564 & 0.346 & 0.919 \\
\hline \multirow{4}{*}{ lost parenting time } & Gender of known or alleged alienating parent & 1.788 & 0.829 & 4.656 & 1 & .031 & 5.980 & 1.178 & 30.350 \\
\hline & Known or alleged alienation case & 2.311 & 0.359 & 41.447 & 1 & $<.001$ & 10.080 & 4.989 & 20.369 \\
\hline & $\begin{array}{l}\text { Unfounded allegations * gender of known or } \\
\text { alleged alienating parent }\end{array}$ & -0.413 & 0.249 & 2.756 & 1 & 0.097 & 0.661 & 0.406 & 1.077 \\
\hline & Intercept & -1.068 & 0.225 & 22.512 & 1 & $<.001$ & -- & -- & -- \\
\hline \multirow{4}{*}{$\begin{array}{l}\text { No change in } \\
\text { parenting time }\end{array}$} & Unfounded allegations & -0.029 & 0.050 & 0.328 & 1 & .567 & 0.972 & 0.880 & 1.072 \\
\hline & Gender of known or alleged alienating parent & 0.342 & 0.264 & 1.672 & 1 & .196 & 1.407 & 0.838 & 2.362 \\
\hline & Known or alleged alienating parent & 1.457 & 0.271 & 28.905 & 1 & $<.001$ & 4.293 & 2.524 & 7.303 \\
\hline & $\begin{array}{l}\text { Unfounded allegations * gender of known or } \\
\text { alleged alienating parent }\end{array}$ & 0.031 & 0.050 & 0.367 & 1 & .545 & 1.031 & 0.934 & 1.138 \\
\hline \multirow{2}{*}{\multicolumn{2}{|c|}{$\begin{array}{l}\text { Test } \\
\text { Overall model evaluation }\end{array}$}} & Value & & $x^{2}$ & $d f$ & $p$ & & & \\
\hline & & & & & & & & & \\
\hline \multirow{3}{*}{\multicolumn{2}{|c|}{ Likelihood ration gender of known or alleged alienating parent }} & -- & & 80.425 & 8 & $<.001$ & & & \\
\hline & & -- & & 10.809 & 2 & .004 & & & \\
\hline & & -- & & 2.346 & 2 & .309 & & & \\
\hline \multirow{2}{*}{\multicolumn{2}{|c|}{$\begin{array}{r}\text { Likelihood ratio test known or alleged alienating parent } \\
\text { Likelihood ratio test interaction effect }\end{array}$}} & -- & & 58.407 & 2 & $<.001$ & & & \\
\hline & & -- & & 4.702 & 2 & .095 & & & \\
\hline \multirow{2}{*}{\multicolumn{2}{|c|}{$\begin{array}{r}\text { Akaike information criterion } \\
\text { Bayesian Information Criterion }\end{array}$}} & 167.406 & & & & & & & \\
\hline & & 205.928 & & & & & & & \\
\hline \multicolumn{2}{|r|}{-2 Log likelihood } & 147.406 & & & & & & & \\
\hline
\end{tabular}




\section{Appendix A}

\section{Codebook descriptions}

\section{Main page}

\begin{tabular}{|c|c|}
\hline Case Number & Sequential number assigned to the case (pdf file name assigned) \\
\hline Trial level motion(s) & $\begin{array}{l}\text { List all motions at the trial-level that were heard and led to the } \\
\text { appeal (e.g., modification of parenting time, enforcement of } \\
\text { parenting time, emergency motions to restrict parenting time) }\end{array}$ \\
\hline Appellate reason & $\begin{array}{l}\text { List all bases provided for reasons of the appeal (e.g., due process } \\
\text { concerns, misapplication of law [specify the law]) }\end{array}$ \\
\hline $\begin{array}{l}\text { Number of abuse allegations } \\
\text { towards the mother cited in } \\
\text { case }\end{array}$ & $\begin{array}{l}\text { Total number of allegations made about the mother. Count } \\
\text { allegations made to multiple agencies (CPS, police) once if related to } \\
\text { the same offense. If same-sex couple, label this as parent } 1\end{array}$ \\
\hline $\begin{array}{l}\text { Number of abuse allegations } \\
\text { towards the father cited in } \\
\text { case }\end{array}$ & $\begin{array}{l}\text { Total number of allegations made about the father. Count } \\
\text { allegations made to multiple agencies (CPS, police) once if related to } \\
\text { the same offense. If same-sex couple, label this as parent } 2\end{array}$ \\
\hline $\begin{array}{l}\text { Party/parties who alleged or } \\
\text { found PA }\end{array}$ & $\begin{array}{l}\text { List all individuals who stated or found that PA was an issue in the } \\
\text { case (e.g., a parent, therapist, custody evaluator, court personnel) }\end{array}$ \\
\hline Basis for PA opinion & $\begin{array}{l}\text { List specific details about what is provided in support of believing PA } \\
\text { is an issue for the family for each party (above) }\end{array}$ \\
\hline $\begin{array}{l}\text { Basis for rejection of PA } \\
\text { opinion }\end{array}$ & $\begin{array}{l}\text { If PA was clearly described in the judgement as being unfounded, } \\
\text { give details about this. If it is not described, enter n/a }\end{array}$ \\
\hline Custody change at trial level & Was custody changed because of the trial-level ruling (if described)? \\
\hline If yes: & $\begin{array}{l}\text { Describe the change (e.g., joint custody to primary custody to } \\
\text { mother or father) }\end{array}$ \\
\hline $\begin{array}{l}\text { Custody change at appellate } \\
\text { level }\end{array}$ & $\begin{array}{l}\text { Was custody changed because of the appellate-level ruling (if } \\
\text { described). If the appellate ruling upholds the change at trial level, } \\
\text { then this answer would be "no." }\end{array}$ \\
\hline If yes: & $\begin{array}{l}\text { Describe the change (e.g., joint custody to primary custody to } \\
\text { mother or father) }\end{array}$ \\
\hline $\begin{array}{l}\text { Did a parent lose all custody } \\
\text { of the child(ren)? }\end{array}$ & Yes or no \\
\hline If yes: & Which parent lost all custody? \\
\hline Winner & $\begin{array}{l}\text { Which parent "won" the case? This is different than custody. It is } \\
\text { just whether the parent won the appeal. }\end{array}$ \\
\hline
\end{tabular}




\section{Abuse Allegation Page Codes: One page filled out for each accusation of abuse}

\begin{tabular}{|c|c|}
\hline Allegation \# & $\begin{array}{l}\text { Enter sequentially, oldest to most recent (one page made for each } \\
\text { accusation) }\end{array}$ \\
\hline Date of allegation & Date (if provided), year, or enter "no date" if not available \\
\hline $\begin{array}{l}\text { Date abuse was reported to } \\
\text { have occurred }\end{array}$ & $\begin{array}{l}\text { If known, indicate when the alleged abuse actually happened. A time } \\
\text { frame may also have been reported. }\end{array}$ \\
\hline Type of allegation & $\begin{array}{l}\text { Domestic violence, child abuse, child sexual abuse, neglect (only } \\
\text { those allegations made to an authority such as CPS) }\end{array}$ \\
\hline Person(s) making allegation & $\begin{array}{l}\text { List people who made the allegation (e.g., parent, child, anonymous } \\
\text { call) }\end{array}$ \\
\hline Who allegation was made to & $\begin{array}{l}\text { List all parties to whom the allegation was made to (e.g., police, } \\
\text { hospital, CPS, court only, a teacher) }\end{array}$ \\
\hline Accused party/parties & $\begin{array}{l}\text { List the accused party (or parties if multiple; parent, step-parent, } \\
\text { grandparent) of the abuse }\end{array}$ \\
\hline Alleged victim(s) & List all alleged victims (e.g., other parent, children, extended family) \\
\hline Details of "proof" of allegation & $\begin{array}{l}\text { Describe what was used to support the allegation (e.g., picture of a } \\
\text { bruise, child's disclosure) }\end{array}$ \\
\hline Protection order & Was a protection order placed on the accused party? (yes or no) \\
\hline If yes: & $\begin{array}{l}\text { Protection order for which "victim?" } \\
\text { How long? }\end{array}$ \\
\hline Arrest & Was the accused party arrested for the allegation? (yes or no) \\
\hline $\begin{array}{l}\text { Party/parties who } \\
\text { investigated the allegation }\end{array}$ & $\begin{array}{l}\text { Describe all who investigated the abuse allegation (e.g., detective, } \\
\text { CPS worker) }\end{array}$ \\
\hline $\begin{array}{l}\text { Parenting time during } \\
\text { investigation }\end{array}$ & $\begin{array}{l}\text { What contact did the accused party/parties have with the child while } \\
\text { being investigated? E.g., supervised visits, no contact, regular } \\
\text { parenting time }\end{array}$ \\
\hline Outcome of investigation & $\begin{array}{l}\text { Describe what the outcome was: substantiated, unsubstantiated, } \\
\text { false, other }\end{array}$ \\
\hline Court involvement & Was the allegation brought to court (family or criminal)? Y/N \\
\hline If yes: & $\begin{array}{l}\text { What was the final judgement of the court regarding the allegation? } \\
\text { Guilty/not-guilty/no information }\end{array}$ \\
\hline If guilty: & Was parenting time restricted for the guilty parent? $\mathrm{Y} / \mathrm{N}$ \\
\hline PA & Was the allegation used to support a diagnosis of PA? \\
\hline
\end{tabular}

